I.

\title{
Das Heimfallsrecht und die Gütervereinigung im älteren böhmisch-mährischen Recht.
}

\author{
Von \\ Herrn Professor Dr. jur. Wilhelm von Brünneck \\ in Halle a./S.
}

I.

Am 15. April 1406 begnadigt der Bischof Lanek von Olmütz die Einwohner seines Marktfleckens Mödritz mit einem Privileg. Es war, wie in den Eingangsworten gesagt wird, veranlasst durch das umfassende Recht, welches die Dynasten und Grundherm in der Olmützer Diöcese und im Lande Mähren von Alters her gegenüber ihren Hintersassen und wegen der Güter und Fahrniss, welche diese bei ihrem Tode hinterliessen, in Ansprueh nahmen und ausübten. Starb ein Mann oder eine Frau ohne eheliche Leibeserben, oder blieben zwar solche zurück, waren aber von Eltern oder Geschwistern bei deren Lebzeiten abgeschichtet und abgetheilt worden, dann fiel der ganze unbewegliche und bewegliche Nachlass dem Herm des Orts heim, wo der Verstorbene seinen Wohnsitz gehabt hatte.

Dieses Heimfallsrecht erklärt der Bischof für Mödritz mit Zustimmung seines Domkapitels abschaffen oder doch ändern und einschränken zu wollen. Fortan solle beim Tode eines Mödritzer Einwohners männlichen oder weiblichen Geschlechts alles, was sich an Hab und Gut in seinem Nachlass vorfinde, nicht mehr an ihn, den Bischof oder an seine Nachfolger auf dem bischöflichen Stuhl fallen, sondern an die Söhne und Töchter, Geschwister und übrigen Blutsverwandten des Verstorbenen nach Ordnung und Gradesnähe

Zeitschrift für Rechtsgeschichte. XX. Germ. Abth. 
vererben, ungehindert durch eine etwa bei Lebzeiten des Erblassers vorgenommene Gütertheilung ${ }^{1}$ ).

Das vom Bischof Lanek gegebene Beispiel fand bald Nachahmung. Durch ein vom 30. Mai 1406 datirtes Privileg befreite der mährische Landherr (Baron) und Oberst-Kämmerer des Olmützer Zaudengerichts Peter von Krawar die Bürger seiner Stadt Prossnitz von dem Heimfallsrecht in dem bezeichneten Sinne und Umfange, und im Herbst des nämlichen Jahres (2. Oktober 1406) ertheilt der Erzbischof Zbynek von Prag ein Privileg entsprechenden Inhalts seiner Stadt Kojetein ${ }^{2}$ ).

1) Cod. dipl. Mor. XIII (ed. V. Brandl) No.413, ,- in dioecesi Olomucensi et terra Moraviae quaedam corruptela, quae consuetudo patriae dicitur, ab olim inolevit, ut si quis virorum aut mulierum sub cuiuscunque dominio in dicta terra degentium legitimos haeredes sui corporis non habet, etiam si haberet et $a b$ eo divisi forent, decederet $a b$ hac vita, omnia et singula bona tam mobilia quam immobilia, per talem derelicta, ad dominum illius loci, in quo, qui sic obiit, residebat absque contradiccione ipso facto devolvi deberent. Nos - praedictam consuetudinem seu verius corruptelam quoad Mödritz nostrum et eclesiae oppidum ac ipsius oppidanos et incolas - capituli ecclesiae Olomucensis - consensu immutavimus et praesentibus immutamus. Volentes et statuentes, quod - quandocunque et quocienscunque quemcunque oppidanum - oppidi Mödritz sive virilis sive feminei sexus existat, mori contingat, universa bona sua immobilia ac etiam mobilia - per talem derelicta non ad nos aut successores nostros episcopos, sed ad propinquiores consanguineos utriusque sexus, si tamen legitimos haeredes sui corporis non relinquant, debeant absque impedimento devolvi; ad filios tunc et filias, fratres quoque ac sorores et nepotes huinsmodi derelicta ut suo ordine devolvantur, declaramus. Non obstante, si filii filiaeve seu fratres aut sorores, vel alii quicunque consanguinei seu propinqui prius in vita a tali quoad bona sint divisi". - 2) Cod. dipl. Mor. XIII No. 424 und 440. In dem einen dieser Privilegien wird die Befreiung der Bürger vom Heimfallsrecht des Stadtherrn in Zusammenhang gebracht mit der Einführung des Olmützer Stadtrechts in Prossnitz. Es soll dort an die Stelle des Brümner Stadtrechts treten, nach welchem sich bis dahin die Prossuitzer Bürger gerichtet hatten. Wie in Olmütz beim Mangel von Leibeserben der Nachlass eines verstorbenen Bürgers auf seine übrigen Blutsfreunde vererbte, so soll es damit in Zukunft auch in Prossnitz gehalten werden. In dem zweiten Privileg wird die Stadt Kojetein mit dem Stadtrecht von Brünn bewidmet, ihr ausserdem aber noch als besondere Guade die Befreiung vom Heimfallsrecht bewilligt. Diese Thatsachen sind bemerkenswerth. 
Das Privileg des Bischofs Lanek ist jedoch nicht das älteste derartige Privileg. Schon im XIV. Jahrhundert und zwar in den Jahren 1363 und 1364 hatte Albert von Sternberg, früher Bischof von Schwerin, nachher Bischof von Leitomischl in Böhmen ${ }^{1}$ ) das ihm als Herrn der Städte Hof und Sternberg zustehende Heimfallsrecht dahin eingeschränkt, dass es fortan nur noch statthaben sollte, wenn Bürger dieser Städte starben, die weder Leibeserben, noch auch andere nähere Verwandte hatten ${ }^{2}$ ).

Wie aber war es, wenn ein Bürger oder Einwohner der so bevorrechtigten Städte oder Flecken weder Leibeserben noch andere Verwandte hatte, wohl aber wünschte, das, was er besass, von Todes wegen einem Freunde zuzuwenden?

Es ergiebt sich daraus, dass die Verleihung des deutschen Rechts für sich allein noch nicht genügte, um eine damit bewilligte mährische Stadt vor der Ausübung des slavisch-mährischen Heimfallsrechts durch den Herrn der Stadt zu schützen. Es musste der Verzicht hierauf und seine Abschaffung oder richtiger Einschränkung hinzukommen, sei es dass diese mit ausdrücklichen Worten erklärt oder dadurch angeordnet wurde, dass das Privileg den Kindern, oder beim Mangel von solchen, und wenn auch eine letztwillige Verfügung nicht vorlag, den nähern Blutsverwandten ein Erbrecht in den Nachlass des verstorbenen Bürgers eröffnete. S. hierüber, was Brünn selbst angeht, Wenceslai I. regis iura originalia civitatis Brumensis (1243) No. 29. 30. (Rössler S. 353).

1) Vgl. Cod. dipl. Mor. IX No. 313 mit No.387. - 2) Privileg für Hof (Cod. dipl. Mor. IX No. 313): „Nouerint universi - quod Nos Albertus - Episcopus Zwerinensis, dominus in Sternberg, cupientes civitatem nostram in Curiis in suis iuribus et libertatibus ampliari, ipsam et preurbia ipsius nec non incolas, homines et communitatem inibi habitantes ab omni iure devolutionis bonorum cuiuscunque sine legittimis heredibus decedentis, quod ius in volgari Moravico odmirt dicitur, nobis et nostris posteris vt veris dominis competenti pro nobis et nostris posteris liberos facimus et exemptos. Et concedimus ipsis ac in hoc eos priveligiamus, vt quocienscunque aliquis in ipsa civitate nostra et preurbiis ipsius carens legittimis heredibus viam vniuerse carnis ingrederetur extunc bona, per eum relicta non ad nos et posteros nostros, sed ad proximiorem amicum suum devoluantur. - Si autem iam nullus (heres) seu propinquus amicus reperiretur, extune primo bona huiusmodi per decedentem relicta ad nos et nostros posteros deuoluantur". Privileg für Sternberg cod. dipl. Mor. IX No. 334. Ueber das zur Bezeichnung des Heimfallsrechts, soweit es dem Grundherrn zustand, gebrauchte Wort odmirt (odmrt) s. Brandl, Glossar. in bohem.-mor. hist. font. bei diesem Wort. 
Konnte er dem Heimfall seines Nachlasses an den Stadtoder Grundherrn durch Errichtung einer letztwilligen Verfügung vorbeugen? Die älteren Privilegien schweigen hierüber. Auch der Bischof Lanek sagt davon in seinem Privileg für Mödritz nichts. Erst der Erzbischof Zbynek von Prag verbindet in dem Privileg, das er seiner Stadt Kojetein am 2. Oktober 1406 ertheilt, mit der Befreiung vom Heimfallsrechte die weitere Gnadenerweisung, dass die Bürger, wie unter Lebenden, so auch von Todes wegen befugt sein sollen über ihre beweglichen und unbeweglichen Güter zu verfügen. Er knüpft daran nur die Bedingung, es müsse der Bedachte dem Stadtherrn wie seinen Nachfolgern und der Stadtgemeinde selbst wohlgesinnt sein. Das Testament aber sollte in gehöriger Form errichtet und sein Inhalt in dem Stadtbuch vermerkt werden ${ }^{1}$ ).

Die Veräusserungs- und Testirfreiheit wird den Bürgern von Kojetein lediglich und allein mit Rücksicht auf das herrschaftliche Heimfallsrecht eingeräumt. Von einem Wartoder Beispruchsrecht der nächsten Erben, das die Eigenthümer von Liegenschaften gehindert hätte, über diese unter Lebenden oder von Todes wegen beliebig zu verfügen, ist keine Rede. Das Brünner Stadtrecht, mit dem der Erzbischof seine Stadt Kojetein bewidmet, kannte ein solches Recht nicht. Ebenso waren ihm Bestimmungen fremd, welche die Vergabung von Fahrhabe auf dem Siechbette verboten oder erschwerten ${ }^{2}$ ).

1) C. d. M. XIII No. 440: „Insuper - civibus - oppidi Kogetin - uberiorem gratiam facientes concedimus -, quod ex nunc omnes et singuli incolae - heredes et successores ipsorum utriusque sexus possint et valeant universa bona eorum mobilia et immobilia - cuique homini seu personae pro nobis et successoribus nostris ac praedicta communitate volenti vendere, legare, dare - in vita pariter ac in morte. Sic tamen, quod testamentum huiusmodi iuxta consuetudinem ab antiquis observatam temporibus ad instar civitatis Brunensis celebretur ac libro dicti oppidi annotetur". Als Anhalt für die bei der Errichtung letztwilliger Verfügungen zu beobachtenden Formen hatten hiernach die Vorschriften zu dienen, welche in Brünn massgebend waren. - ${ }^{2}$ ) Iura originalia civ. Brunensis (1243), 24b, 30. 31. (Rössler, S. 352-353). Brünner Schöffenbuch 363 (Rössler, S. 165). Stadtrecht von Brünn aus dem Anfang des XIV. Jahrhunderts 77 (41), 83 (47) (Rössler, S. 361-362). 
Es erhellt hieraus, dass, unabhängig von einem Recht der nächsten Erben und selbst da, wo ein solches überhaupt nicht in Frage kam, dem grundherrlichen Heimfallsrecht die Erbschaften der Hintersassen nur durch ein Privileg des Grundherrn selbst entzogen werden konnten. Ohne solches vermochte keiner von ihnen seinen Herrn dadurch auszuschliessen, dass er seine abgeschichteten Kinder oder einen Bruder oder Vetter, mit dem er abgetheilt hatte, oder einen Dritten, mit dem ihn keinerlei verwandtschaftliche Bande verknüpften, letztwillig zu Erben seiner Habe und seiner Güter berief. Das Privileg für Kojetein dient so zur Ergänzung des Inhaltes des an erster Stelle von uns angeführten Privilegs des Bischofs Lanek für Mödritz.

Ist dieses, wie wir sahen, nicht das älteste Privileg, wodurch das Heimfallsrecht eines mährischen Dynasten für die Bewohner einer Stadt oder andern Ortschaft ausser Kraft gesetzt wurde, so reicht es auch nicht aus, um die Bedeutung und die Wirkungen jenes Rechts nach allen Seiten hin erkennen zu lassen. Wenn wir es trotzdem vorangestellt haben, ist das nur deshalb geschehen, weil der Bischof Lanek sich am deutlichsten über den Grund des so weitgehenden Heimfallsrechts der mährischen Dynasten und Herrn ausspricht, indem er es auf die Abschichtung und Gütertheilung zwischen Eltern und Kindern, beziehungsweise unter Geschwistern und andern Verwandten zurückführt. Ferner aber ist Lanek der Einzige, welcher andeutet, wie etwa das fragliche Heimfallsrecht in Mähren diese seine Bedeutung hat erlangen können.

Als Quelle, dem es entsprungen sei, nennt er eine Verkehrung des Rechts (corruptela), die man ein vaterländisches Gewohnheitsrecht heisse, während man richtiger darin eine Rechtsverderbniss oder einen Missbrauch zu erblicken habe ${ }^{1}$ ).

$\mathrm{Ob}$ diese Behauptung der Wahrheit entspricht oder doch nahe kommt, oder aber gänzlich haltlos ist, mag vorerst dahingestellt bleiben. Wir werden im nächsten Abschnitt

1) S. das oben S. 2 n. 1 angeführte Privileg für Mödritz bei den Worten: „quaedam corruptela, quae consuetudo patriae dicitur" und weiter: „Nos - praedictam consuetudinem seu verius corruptelam .... immutamus". 
darauf zurückkommen. Hier sei nur noch bemerkt, dass der König Kasimir III. von Polen im Jahre 1347 das Heimfallsrecht, welches der dortige Adel wegen des Nachlasses seiner Kmeten, Bauern und andern Hintersassen für sich in Anspruch nahm und geltend machte, wenn diese keine Leibeserben hatten, ebenfalls für einen Missbrauch erklärte, der darum nicht ferner geduldet, sondern abgeschafft sein sollte ${ }^{1}$ ).

\section{II.}

Dem Heimfallsrecht, welches sich die Dynasten und Grundherrn am Nachlass des im Bereiche ihrer Gewalt versterbenden Hintersassen zuschrieben, entsprach das Heimfallsrecht des Königs von Böhmen oder des Markgrafen von Mähren [napad Královsk'́ $\left.{ }^{2}\right)$ ] in Ansehung der Güter und der fahrenden Habe der Barone und Wladyken (Ritter und Adligen niedern Grades) im ganzen Lande. Es fand überall Anwendung, wo ein Adliger starb, der keine Leibeserben oder doch nicht Söhne oder Töchter, noch auch Brüder oder Schwestern hinterliess, welche bis zu seinem Ableben mit ihm in der elterlichen Were gesessen oder doch in ungetrennten Gütern sich befunden hatten ${ }^{3}$ ).

Unbestritten war freilich dieses königliche Heimfallsrecht nicht. Am 25. December 1310 legte der böhmischmährische Adel dem neuerwählten Könige Johann von Luxemburg ein von ihm entworfenes Verzeichniss der Landesfreiheiten vor und bat um ihre Anerkennung, beziehungsweise Bewilligung. Darunter befand sich ausser andern

1) Stat. Casimiri III. Visliciae a. 1347 promulgat. 55 (Bantkie, Ius Polonic. p. 65-66): „Abusiva consuetudine noscitur esse observatum, quod, cum aliqui kmethones seu rustici vel alii civiles homines absque prole de hac luce decedunt, ipsorum omnia bona, mobilia et immobilia nomine vulgariter púscizna, domini eorumdem consueuerunt occupare, unde nos eandem consuetudinem, ut iuri contrariam et absurdam reputantes, statuimus: quod de bonis eorumdem decedentium, si tantum reperiatur in eisdem bonis, calix pro marca cum media ecclesiae parochiali dandus comparetur, reliqua vero bona ad proximos consanguineos, vel affines, cessante quolibet impedimento, devolvantur, prout aequitas et iustitia suadent". $-{ }^{2}$ ) Brandl, Glossar. verb.: napad. - ${ }^{3}$ ) Čelakovský, Das Heimfallsrecht auf das frei erbliche Vermögen in Böhmen S. 4. 
Rechten ein erweitertes gesetzliches Erbrecht. Es sollten, wenn beim Tode Adliger, die weder unter Lebenden noch von Todes wegen über ihre Güter verfügt hatten, keine Söhne nachblieben, die Töchter, und wenn überhaupt keine Leibeserben vorhanden wären, die nähern Blutsverwandten beiderlei Geschlechts bis zum dritten Gliede zur Erbfolge in die Güter und das sonstige Vermögen, das den Nachlass bildete, berufen sein. Dabei wurde zwischen abgeschichteten und nicht abgeschichteten Kindern oder zwischen Geschwistern, die unter einander die väterlichen Güter getheilt hatten, und andern, die bis zum Tode des einen oder des andern von ihnen in ungetrennten Gütern mit einander verblieben waren, nicht unterschieden. Der Umstand, ob eine Abschichtung oder Gütertrennung stattgehabt hatte oder nicht, blieb unerwähnt.

Ein solches Erbrecht war, wie der Adel den König in dem ihm vorgelegten Entwurf sagen liess, nicht ein neues, sondern das alte wiederhergestellte, nur zu erneuernde Recht, welches ehemals Geltung gehabt hatte und erst unter der Regierung einiger seiner Vorgänger durch Nichtanwendung ausser Kraft gesetzt und so stillschweigend widerrufen worden war').

Diese Behauptung erscheint nicht ungegründet. Die mit den iura suppanorum gleichbedeutenden Konradischen oder Ottonischen Statuten, welche noch in die zweite Hälfte des XII. Jahrhunderts zurückgehen, dann aber im XIII. Jahrhundert und zwar 1222 für die Znaymer, 1229 für die Brünner Zupa ${ }^{2}$ ) durch Ottokar I., im Jahre 1237 für

1) „Antiquum - regnicolarum ipsorum ius, quod aliquorum praedecessorum nostrorum, regum Boemorum, temporibus abolitum et abusu revocatum fuerat, renovantes, decernimus et in perpetua de cetero volumus stabilitate manere, quod quicunque filiis masculis non relictis decesserit, filiae superstites in hereditate et bonis paternis succedant. Si autem nec filios nec filias habens et nulla de bonis suis in vita vel in morte dispositione facta decedat, proximiores usque ad quartum consanguineitatis gradum masculini vel feminini sexus heredes in bonis suis omnibus et hereditate succedant". Libertates regno et incolis regni Boemiae a Ioanne rege ante coronationem promissae. 1310 25. Decembris (Cod. iur. bohemici ed. H. Jireček, II., s. p. 21). - ${ }^{2}$ ) Das Wort Zupa bezeichnete ursprünglich den Stamm, indem das böhmische Volk in 
v. Brünneck,

die Lundenburger Provinz durch Herzog Ulrich erneuert und bestätigt wurden, bestimmten, dass, wenn ein Adliger bei einem Diebstahl ${ }^{1}$ ) ergriffen und gehenkt werde, sein liegendes Erbe (haereditas) dem Könige ledig werde und verfalle. Sonst aber und abgesehen von einer aus dem bezeichneten Grunde eintretenden Konfiskation solle beim Tode eines Adligen, der keine Söhne, wohl aber Töchter habe, sein Erbe auf die Töchter und zwar zu gleichen Theilen, und wenn auch diese nicht vorhanden wären, auf die nächsten Erben übergehen ${ }^{2}$ ). Dass nur allein unabgeschichtete Söhne und nicht ausgestattete Töchter oder solche Geschwister und Geschwisterkinder u. s. w. erben durften, welche mit dem Erblasser in ungetrennten Gütern lebten, davon verlautet nichts. Andererseits ward in jenen älteren Statuten aber auch ebensowenig mit Deutlichkeit ausgesprochen, dass eine erfolgte Abschichtung oder Gütertheilung keinen Einfluss hatte und das gesetzliche Erbrecht nicht irgendwie berührte.

Daher entsteht denn die Frage, ob die Ausschliessung der abgeschichteten Kinder von der Erbschaft der Eltern und namentlich des Vaters, oder die Ausschliessung der Brüder oder Schwestern und andern Verwandten, die mit den Verstorbenen eine Gütertheilung vornahmen, sich etwa von selbst aus dem älteren böhmisch-mährischen Rechte ergab und als eine nothwendige Folge und Wirkung des Wesens und der Bedeutung der Familie anzuerkennen ist

älterer Zeit in Stämme zerfiel, deren Grundlage die Hausgemeinschaften und deren Vereinigung zu Dorfgemeinden bildeten. Später aber verband man mit dem Worte den Begriff eines territorialen Bezirks. Tomaschek, Deutsches Recht in Oesterreich im XIII. Jahrhundert, S. 4.

1) Cod. dipl. Mor. V. Suppl. No. 12; II. No. 194, II. No. 283. Vgl. dazu Tomaschek a. a. O. S. 4 ff. - ${ }^{2}$ ) S. die Urk. Königs Ottokar I. vom Jahre 1222 enthaltend die Erneuerung und Bestätigung der im Text genannten Statuten für die Znaimer Zupa (Cod. dipl. Mor. V. Suppl. No. 12) bei den Worten: "Quando aliquis nobilis capitur in furto et suspenditur et non habeat prolem, hereditas ipsius regi cedat - si quis autem non habuerit filium et habuerit filias, ad illas deveniat hereditas equaliter, et si non sint, hereditas deveniat ad proximos heredes". Die beiden andern von Ottokar I. und Herzog Ulrich her'rührenden Erneuerungen der iura suppanorum stimmen in den erbrechtlichen Vorschriften mit dem Inhalte der Urkunde von 1222 fast buchstäblich überein und schalten nur hinter den Satze: „si quis autem non habuerit filium" noch die Worte ein: "vel filios". 
und des Verhältnisses, in welchem die einzelnen Blutsverwandten in älterer Zeit zur Familie standen. Celakovský ${ }^{1}$ ) will diese Frage bejaht wissen. Ihm zufolge brachten es die Grundsätze des altböhmischen Rechts mit sich, dass ein abgesondertes Familienmitglied, und war es auch der eigene Sohn oder die eigene Tochter jedweden Erbrechts am Stammgute der Familie verlustig ging, selbst wenn die Familie, von der es sich abgesondert hatte, gänzlich ausgestorben war.

Ich vermag dieser Meinung nicht beizutreten. Sie hält m. E. die verschiedenen Phasen in der historischen Entwickelung des böhmisch-mährischen Rechts nicht gehörig auseinander. Solange noch die Familie bei den Czechoslaven den Charakter der alten slavischen Hauskommunion ${ }^{2}$ ) festhielt, war, weil es kein Sondereigenthum gab, die Entstehung eines Erbrechts nicht möglich. Gehörte doch das gesammte unbewegliche wie bewegliche Vermögen allen Familiengliedern, und nur die Verwaltung und Vertretung der Familie und ihrer Rechte befand sich bei dem Familienältesten. Während innerhalb des Familienverbandes in absteigender Linie ein Einrücken der überlebenden Kinder oder Enkel u. s. w. in die Stelle der verstorbenen Eltern und deren frei gewordenen Antheil am Familiengute, in aufsteigender Linie ein Zurückfallen der Antheile verstorbener Kinder u. s. w. an die Eltern oder Grosseltern, in der Seitenlinie aber ein Anwachsungsrecht wegen der erledigten Antheile zum Vortheil der überlebenden Geschwister u. s. w. stattfand, musste ein Austreten aus der Kommunion und eine Abschichtung, soweit solche überhaupt geschehen durfte, für die abgesonderten Verwandten, weil sie aufhörten Miteigenthümer zu sein, den Verlust jedes Rechts am Familiengute herbeiführen. Es fiel dieses eben noch völlig.mit dem Miteigenthum zusammen und liess keinen Raum für ein davon verschiedenes Erbrecht.

Anders aber wurde es, als im Laufe der Zeit der Vater oder Grossvater aus dem Vertreter der Familie und dem

1) Čelakovský, Das Heimfallsrecht in das frei erbliche Vermögen S. 4. - 2) S. hierüber Paul Turu, Slawisches Familienrecht (Strassburger Inauguraldissertation) 1874 S. $2 \mathrm{ff}$. 
Verwalter des Familiengutes zu dessen alleinigem Eigenthümer wurde. Da schwächte sich das Miteigenthum, das die sämmtlichen in der Kommunion befindlichen Familienglieder zu gesammter Hand gehabt hatten, zu einem Wartrecht (nápad) ${ }^{1}$ ) am Familiengute ab. Neben diesem hatte nunmehr ein wirkliches Erbrecht Platz. Ein solches fand sich schon, wie wir sahen, in den Konradisch-Ottonischen Statuten anerkannt. Auch jetzt konnte zwar die Thatsache, dass die abgeschichteten Kinder oder die übrigen abgesonderten Verwandten, weil sie mit der Abschichtung oder Abtheilung aus dem engerén Kreise der wartberechtigten Familienglieder ausschieden, es rechtfertigen, dass sie im Erbrechte den nicht abgeschichteten Kindern oder den in ungetrennten Gütern verbliebenen Geschwistern $u$. s. w. nachgestellt wurden. Warum sie aber, wenn neben und ausser ihnen keine unabgeschichteten Kinder, noch andere ungesonderte Verwandte mehr vorhanden waren, von der Erbschaft eines verstorbenen Blutsverwandten ausgeschlossen und ihnen jedes Erbrecht vorenthalten sein sollte, ist nicht einzusehen. Welcher Grund lag da vor, um den Nachlass des Todten als erblosen zu behandeln? Das böhmisch-mährische Familienrecht bietet in diesem späteren Stadium seiner Entwicklung dafür keinen Anhalt.

Es ist daher die Annahme des Bischofs Lanek, dass die Dynasten und Herrn durch missbräuchliche Anwendung der ihnen zustehenden Machtbefugnisse sich ein Recht auf den Nachlass ihrer Hintersassen vor noch vorhandenen abgeschichteten Kindern und abgesonderten Geschwistern und andern Verwandten verschafft und diesen damit die Möglichkeit ihre Eltern oder Geschwister u. s. w. zu beerben genommen haben, durchaus wahrscheinlich. Ein Gewohnheitsrecht erwuchs hieraus erst, nachdem das bezeichnete gewaltsame Verfahren längere Zeit hindurch fortgesetzt war, ohne dass man dagegen von irgend einer Seite Widerspruch erhoben oder mit Erfolg Widerstand geleistet hätte.

Nicht weniger glaubhaft aber ist die Behauptung des

1) Tomaschek, Recht und Verfassung der Markgrafschaft Mähren im XV. Jahrhundert S. 37. 
mährisch-böhmischen Adels in den von ihm dem König Johann vorgelegten Landesfreiheiten, dass das Heimfallsrecht des Königs in Ansehung der beim Tode von Leuten adligen Standes und ihrer im Nachlass befindlichen unbeweglichen und beweglichen Güter seine Bedeutung und Ausdehnung dem Umstande verdankt, dass einige der früheren Könige das schon geltend gewesene, weitergehende Erbrecht, ohne Rücksicht auf vorhandene, an sich erbberechtigte Verwandte, wiederum eingeschränkt und ihm engere Grenzen gezogen haben, als das Landesrecht es verlangte.

Der König Johann ging auf die Wünsche des Adels wegen einer Erweiterung des Erbrechts nicht ein. Der Adel Böhmens erhielt deshalb überhaupt keinerlei Zusicherung. In Böhmen wurde nach wie vor das Heimfallsrecht in allen Fällen zur Geltung gebracht, wann Adlige starben, denen weder unabgeschichtete Kinder noch ungesonderte Geschwister oder Geschwisterkinder nachblieben ${ }^{1}$ ). Dem mährischen Adel ertheilte der König zwar am 18. Juni 1311 ein Privileg, dessen Wortlaut der Proposition der Landesfreiheiten vom Jahre zuvor, soweit es sich darin um das gesetzliche Erbrecht handelte, gerecht zu werden schien. Er verordnete, das königliche Heimfallsrecht solle, abgesehen von einer Verwirkung wegen begangener Verbrechen, erst Platz greifen, wenn weder Kinder, Söhne oder Töchter, noch auch Brüder oder Bruderkinder bis zum dritten Gliede einschliesslich vorhanden wären. Die Frage aber, ob unter den zur Erbfolge in die Güter adliger Grundbesitzer ${ }^{2}$ ) berechtigten Verwandten die abgeschichteten Söhne oder verheirathete und ausgestattete Töchter und ebenso die Geschwister mit inbegriffen waren, die mit dem Verstorbenen die väterlichen Güter getheilt hatten, wurde mit Stillschweigen übergangen.

1) S. Celakowský a. a. O. S. 7 und das aus Emler, Reliquiae tabular. terrae Boemiae I. S. 401 angeführte Weisthum des Landrechts (Zaudengerichts) vom Jahre 1321. - ${ }^{2}$ ) Cod. iur. Bohem. (Jireček) II, 1 p. 25 No. 16: „Insuper communi voto parentum affectantium successionem suam devolvi ad posteros, clementer assentientes nolumus, quod liberis, filiis et filiabus seu fratribus, eorumve filiis infra quartam generationem extantibus, alicuius nostri subditi bona ad nos tamquam vacantia, nisi propter crimen confiscanda forent, devolvantur seu nostro erario applicentur". Cod. dipl. Mor. VI No. 49. 
Auch für Mähren hielt vielmehr der König an der, wie er meinte, in Böhmen herrschenden Rechtsauffassung fest und wollte demgemäss das Heimfallsrecht nicht fahren lassen, so oft Güter in Böhmen oder Mähren in Frage kamen, die einer von mehreren kinderlos verstorbenen Brüdern allein und nicht in Gemeinschaft mit einem andern Bruder oder einer Schwester besessen hatte. Er bezeichnete es als eine besondere Gnade, wenn er einmal dem einen oder dem andern von mehrern Brüdern oder deren Söhnen, unbeirrt durch eine unter ihnen stattgehabte Gütersonderung, das Recht sich gegenseitig zu beerben bewilligte ${ }^{1}$ ). Fast mit denselben Worten, deren sich König Johann im Privileg von 1311 bedient hatte, machte Kaiser Karl IV. dem Adel Böhmens, gelegentlich der Bestätigung der Freiheiten und Rechte des Landes im Jahre 1347, das Zugeständniss, ein Nachlass solle erst dann an den König fallen und für den königlichen Schatz eingezogen werden, wenn er von einem adligen Landsassen herrühre, welcher weder Leibeserben hatte, noch Seitenverwandte bis zum dritten Gliede einschliesslich $^{2}$ ). Eine nähere Bestimmung aber, welche Trag-

1) S. die Urk. des König Johann vom 14. März 1335 für den Ritter Holub den Aelteren und seine Brüder Ulrich, Pešerk, Witeb und Přibik (Cod. dipl. Mor. VII No. 227): „Iohannes - attendentes grata, accepta et fidelia servicia que - antiquus Holub miles, ac Ulricus Pesco, Wytgo et Przibo fratres eius - exhibuerant - , ipsis - hanc gratiam - providimus faciendam videlicet, si prefatorum fratrum aliquem vel aliquis sine heredibus legittimis de hac vita migrare contingerit, per cuius aut per quorum mortem bona sua vel ipsorum sita in regno nostro Boemie aut in terra Moravie seu alibi ubicunque iuxta approbatam nostri Boemie (regni) sententiam ad nos devolverentur, volumus et - ipsis concedimus generosius et indulgemus, ut predicta bona et possessiones ac hereditates - illius seu illorum predictorum fratrum, qui medio tempore decedent, ad predictos fratres eius et ad quemlibet ipsorum prolem viventem pleno iure et libertate, prout ipse tenuit et possedit, spectare et redundare debeant et tenebuntur". - 2) "Insuper communi voto parentum affectantium successionem et bona devolvi ad posteros clementer assentientes volumus, quod liberis filiis et filiabus seu fratribus eorumve filiis usque ad quartam generationem non existentibus alicuius subditi nostri bona ad nos, tamquam ad regem vacantia, nisi propter crimen confiscanda forent, devolvantur seu nostro erario applicentur" (Pelzel, Kaiser Karl IV. I. Bd. U.-B. No. 192. Cod. dipl. Mor. VII No. 746). 
weite man diesem Privileg geben sollte, unterblieb. Der Zweifel, ob es sich auf abgesonderte Familienglieder miterstreckte, bestand fort. Es wurde hierüber auch in der Folgezeit noch vielfach vor dem Hofgericht in Prag gestritten $^{\mathrm{t}}$ ).

Wie Karl IV. selbst den Sinn dieser Bestimmung seines Privilegs verstanden wissen wollte, lässt sich aus der Majestas Carolina entnehmen. Nach Art. 65 soll zwar der Nachlass beider Eltern des Vaters wie der Mutter nicht sowohl an die unter väterlicher Grewalt gestandenen, im selben Hause mit den Eltern lebenden, sondern auch an die emancipirten und abgeschichteten Söhne erben. Dahingegen wird den Eltern das Erbrecht in das Vermögen der emancipirten und abgeschichteten Kinder ohne Unterschied des Geschlechts abgesprochen. Es soll nach Reichsrecht und alter Gewohnheit gemäss an die königliche Kammer fallen, wenn solche ohne ihrerseits Leibeserben zu hinterlassen, sterben ${ }^{2}$ ). Wegen der Töchter unterscheidet die Maj. Car. zwischen den beim Tode des Vaters oder der Mutter im elterlichen Hause lebenden unverheiratheten und den Töchtern, welche entweder noch verheirathet sind oder doch schon verehelicht waren und Wittwen geworden sind. Während die unverheiratheten, noch unausgestatteten Töchter zur Erbfolge in die Liegenschaften und das übrige Vermögen der Eltern verstattet werden, bleiben die verheiratheten oder verwittweten Töchter vom Erbrecht ein- für allemal ausgeschlossen, so

1) Celakovský a. a. O. S. 7. - ${ }^{2}$ ) Maj. Carolina (Cod. iur. Boh. ed. Jireček II, 2 p. 100. 197) Art. 65: „De hereditatibus devolvendis ad filios vel parentes. $\$ 1$. Hereditates parentum utriusque serus, scilicet patris et matris, quas ad filios ex eorumdem parentum corporibus legitime procreatos deferri regaliter volumus et sancimus, non solum de liberis in paterna potestate sistentibus seu cum ipsis parentibus simul cohabitantibus, sed etiam de emancipatis seu divisis a parentibus supradictis intelligimus. (Licet enim personarum et locorum remotio inducatur, non propterea sanguinis necessitudo, quae nulla potest ratione divelli, aliquatenus separatur.) $\$ 2$. Si filii vel filiae, divisi seu emancipati a parentibus eorum, superstitibus parentibus ipsis decedant: eorum hereditates et bona non ad parentes ipsos, sed ad regiam cameram de iure regni et antiquissima consuetudine devolvantur". 
dass, wenn keine andern unabgeschichteten Kinder da sind, der elterliche Nachlass dem Fiskus heimfällt. Begründet wird diese Versagung des Erbrechts damit, weil die Töchter sich mit der Ausstattung, die sie bei ihrer Verheirathung empfingen, begnügen müssten, indem sie durch diese endgültig abgefunden seien ${ }^{1}$ ). Wie sie die Eltern nicht beerben, sollen sie darum auch nicht Erben eines nach dem Ableben des Vaters oder beider Eltern verstorbenen Bruders oder einer dann verstorbenen Schwester werden, wenn sie vor oder nach dem Tode der Eltern heiratheten und im letzteren Falle behufs ihrer Ausstattung von dem Bruder oder der unverheiratheten Schwester einen Theil der väterlichen oder mütterlichen Güter erhielten ${ }^{2}$ ). Was zu geschehen hatte, wenn, nachdem der Vater oder nachdem beide Eltern verstorben waren, einer von mehreren Brüdern oder Brudersöhnen starb, und welchen Einfluss der Umstand hatte, ob der überlebende Bruder oder Vetter mit dem verstorbenen sich in die väterlichen oder grossväterlichen Güter getheilt hatte, darüber sagt die Maj. Car, nichts. Es kann aber wohl keinem Zweifel unterliegen, dass nach der Willensmeinung Karls IV. der Bruder oder Vetter keinen Anspruch auf den Nachlass des verstorbenen, von ihm gesonderten Bruders oder Vetters haben sollte. Es spricht dafür die Analogie der Bestimmungen über die Versagung des Erbrechts an die Eltern wegen des Nachlasses der von ihnen abgeschichteten Söhne und über die Ausschliessung der verheiratheten und ausgestatteten Schwester von der Succession in die Güter der Brüder oder der unverheiratheten Schwestern, mit welchen sie abgetheilt hatten ${ }^{3}$ ).

1) Maj. Car. Art. 65. \$3. „De iure et consuetudine regni nostri filiae nuptae aut viduae in bonis et hereditatibus defunctorum parentum non succedunt, quae liberis aliis ex dictis parentibus non extantibus, ad fiscum regium non est dubium pertinere; cum contentae stare debeant dotibus, quae ex dictis hereditatibus, vel alias ab eorum parentibus habuerunt. -- $\$ 4$. Innuptas vero filias, a parentibus nou divisas, in bonis et hereditatibus succedere ommino permittimus et iubemus". - ${ }^{2}$ ) Maj. Car. Art. 67. „De hereditatibus collateralium. Sicut nuptas aut viduas in bonis et hereditatibus parentum succedere prohibemus: multo magis intelligere se debent esse exclusas a successionibus fratrum vel sororum omnium eorundem", - 3) Vgl. Maj. Car. Art. $65 \$ 2$ u. Art. 67. 
Die Majestas Carolina hat bekanntlich nicht Gesetzeskraft erlangt. Nachdem die Stände auf dem Landtage zu Prag vom Jahre 1355 ihre Genehmigung verweigert hatten, zog Karl IV. den Entwurf zurück, indem er erklärte, dass weder er, noch seine Nachfolger, noch die Barone des Königreichs an die darin enthaltenen Bestimmungen gebunden seien, sondern beiden Theilen, dem Könige wie den Ständen der Gebrauch und Genuss der alten, durch Gewohnheit überlieferten Rechte unbenommen bleibe und freistehe ${ }^{1}$ ).

Dennoch erhielt sich die Maj. Carolina in grossem Ansehen. Nicht nur die übrigen Landeseinwohner, sondern auch die Stände und die in ihnen vertretenen und vereinigten Barone und Adligen selbst pflegten in der Folgezeit darauf Rücksicht zu nehmen und sich auf das darin Gesagte zu berufen. Wurde der Gesetzentwurf Karls IV. damit auch nicht als Ganzes gewohnheitsrechtlich recipirt, so bekam doch sein Inhalt insoweit eine gesetzesgleiche Kraft und Bedeutung, als darin das ältere, früher schon im Lande geltende Recht einbegriffen war ${ }^{2}$ ). Darunter fällt auch die Vorschrift des Art. 65, dass die emancipirten und abgeschichteten Söhne zur Erbfolge in die Güter und das übrige Vermögen der Eltern zugelassen sein sollen. Entsprach doch das hiermit von Karl IV. gemachte Zugeständniss den Wünschen des böhmisch-mährischen Adels und der von diesem vertretenen Meinung, es sei das gesetzliche Erbrecht äIterer Zeit ein für ihn günstigeres und weitergehendes gewesen und erst später von den Königen zu Gunsten ihres Heimfallsrechts, und um diesem eine grössere Ausdehnung zu verschaffen, enger begrenzt und beschränkt worden.

Dahingegen wurde im Uebrigen streng daran festgehalten, dass Familienglieder, welche gesondert und den Gütern nach getrennt waren, einander nicht beerben durften, und dem Heimfallsrecht des Königs in allen Fällen stattzugeben sei, wann Adlige starben, denen nur ausgestattete Töchter oder Eltern oder Geschwister oder andere Verwandte nach-

1) S. das hierüber ausgefertigte Patent des Kaisers datirt Pragae 2. Nonas Oct. 1355 Cod. iur. Boh. (Jireček) II, 2 S. 101. - 2) Jireček in den Vorbemerkungen zu seiner.Ausgabe der Maj. Car. (Cod, iur. Boh. II, 2 p. 104). 
blieben, die von ihnen abgetheilt waren. Noch im Jahre 1495 konnte Victorin Cornelius von Vsehrd (Wsehrd) in seinem Buche von den Rechten und Gerichten der Landtafel Böhmens lehren, ,dass sämmtliche Caducitäten dem“" seiner Ansicht nach, ,althergebrachten und ältesten Rechte gemäss, falls Jemand ohne Leibeserben zu hinterlassen, und ohne irgend Jemandem sein Eigenthum verschrieben zu haben, starb, dem Könige zufallen und keineswegs den Anverwandten, ausser sie wären unabgetheilt"1). Der Streit zwischen dem Adel und dem Könige wegen des Heimfallsrechts hörte darum aber doch nie ganz auf. $\mathrm{Zu}$ wiederholten Malen, beim Tode Wenzels IV. 1419 und während der Herrschaft des Königs Georg Podiebrad, verlangten die Stände, der König solle keine Güter im Lande als heimgefallen einziehen, es sei denn, dass Jemand ohne letztwillige Verfügung und ohne Blutsverwandte zu hinterlassen mit Tode abgehe ${ }^{2}$ ). Erst zu Ausgang des Mittelalters kam es zur Erfüllung der hierauf gerichteten Wünsche des Adels. Im Jahre 1497 überliess König Wladislav, mit Vorbehalt des ihm als obersten Lehnsherrn wegen des Heimfalls der Lehngüter zustehenden Rechts, seiner Herrschaft und Ritterschaft (den Baronen und Adligen niedern Grades) die Anfälle Todes halber, welche er bis dahin in Bezug auf die freien Erbgüter gehabt hatte. Diese sollten sammt allen damit verknüpften Gerechtsamen nicht mehr an ihn oder an seine Nachfolger fallen, sondern, wenn Jemand starb, der keine leiblichen und unabgetheilten Erben hinterliesse, noch auch letztwillig darüber verfügt hätte, an seine nächsten Verwandten in der männlichen Linie, beim Abgange der Schwertmagen aber an die nächsten weiblichen Verwandten erben. Den Letzteren werden ausdrücklich die ausgestatteten Töchter und Schwestern gleichgestellt und nur darin den unverheiratheten Töchtern oder Schwestern nachgesetzt, dass beim Mangel von Söhnen die unausgestatteten Töchter sogleich nach dem Vater, die unausgestatteten Schwestern nach den

1) Čelakovský a. a. O. S. 14. Das Rechtsbuch des Vsẹhrd war mir leider hier nicht zugänglich. Ueber Vsehrd vgl. F. Palacky, Geschichte Böhmens S. 423. - ${ }^{2}$ ) Celakovský a. a. O. S. 9-11. 
Brüdern oder Vettern folgen, dahingegen die verheiratheten Töchter oder Schwestern erst erben sollen, wenn beim Mangel von Söhnen keine unausgestatteten Töchter, beim Fehlen von Brüdern oder Vettern keine unausgestatteten Schwestern mehr vorhanden sind ${ }^{1}$ ).

\section{III.}

Das grundherrliche Heimfallsrecht begrenzte nicht allein, wie wir festgestellt haben, das gesetzliche Erbrecht auf den Kreis der unabgeschichteten Nachkommen und sonstigen unabgetheilten Verwandten, sondern nahm den Hintersassen auch die Freiheit von Todes wegen über ihren Nachlass zu verfügen, um das, was sie an Liegenschaften oder Fahrniss besassen, mit Ausschliessung des Herrn, einem abgetheilten Verwandten oder auch einem Dritten zuzuwenden ${ }^{2}$ ).

Nicht anders verhielt es sich mit den Wirkungen des Heimfallsrechts des Königs in Hinsicht der Güter der Barone und übrigen Adligen. Es bildete ein rechtliches Hinderniss gegen irgend welche Verfügung von Todes wegen, welche Leute von Adel über ihren Nachlass treffen mochten, einerlei ob es sich um ihre unbeweglichen Allodialgüter handelte,

1) Lünig, Corp. iur. feudal. II S. 218-219. „Wir Wladisslaus haben diese folgende Begnadigung der Herrschafft und Ritterschafft gethan, dass wir ihnen alle die Anfälle Todes halber, auf Vns, als einen böhmischen König gefallen, als nemlich freye Erb-Güter samt allem Recht, wozu einer Recht und Gerechtigkeit hat, ausserhalb Lehen-Güter - haben nachgelassen und geschenkt, also dass sie auf ewige künfftige Zeit nicht mehr auf Vns, oder künfftigen König fallen sollen, in nachfolgender Gestalt und Meynung, so jemandt Todts halben ohne Erben und ohne Testament abgehet, und hat einen rechten natürlichen Bruder vom Vater, der von ihm abgetheilet ist, so soll sein verlassen Gut durch einen Anfall für allen auf ihn fallen, hat er aber keinen Bruder, so soll es fallen auf seine leibliche Tochter, die von ihm ausgesetzet ist, hat er aber keine Tochter, soll es fallen auf seine leibliche Schwester, die auch ausgesetzet ist, ist aber keine leibliche Tochter noch Schwester vom Vater her, so soll der Fall gehen auf den nächsten blutsverwandten Freund nach dem Schwerdt -, aber die unausgesetzte und unverheirathete Töchter und Schwestern, wo keine Mannes-Erben vorhanden, die seynd und bleiben in alle wege Erbnehmer nach ihrem Vater vnd nach ihrem Bruder oder nach ihren ungetheilten Vettern". - ${ }^{2}$ ) S. oben S. 4.

Zeitschrift für Rechtsgeschichte. XX. Germ. Abth. 
oder um die Fahrhabe. Die Fähigkeit und Befugniss zur Errichtung eines letzten Willens konnte ein Adliger allein durch Gewährung eines sog. Majestäts - oder Machtbriefes erlangen, mit dem ihn der König oder der Markgraf begnadigte $^{1}$ ). Nur dadurch wurden die Wirkungen des Heimfallsrechts für ihn und seine Güter wie für diejenigen Personen beseitigt und ausser Kraft gesetzt, denen er solche nach seinem Tode zuwenden wollte und vermachte.

Während innerhalb der Grundherrschaften die Hintersassen, welche keine Leibeserben oder doch keine unabgeschichteten Kinder oder Kindeskinder, noch auch andere unabgetheilte Verwandte hatten, ihren künftigen Nachlass dem Heimfallsrechte ihres Herrn auf keine Weise zu entziehen im Stande waren ${ }^{2}$ ), schuf sich dahingegen der Adel eine Einrichtung, die geeignet war nicht allein da, wo solches versagt war, das gesetzliche Erbrecht zu ersetzen, sondern auch eine letztwillige Verfügung und die Nach-

1) Als Beispiel diene das Privileg des Markgrafen Prokop für Johann von Neuhaus vom 24. April 1401 (Cod. dipl. Mor. XIII No. 105): „Facimus graciam specialem - quod ipse - dominus Iohannes universa et singula sua bona hereditaria, mobilia et immobilia - que in presencia obtinet in terra nostra Moravie, vel acquirere poterit in futurum, dare, donare et assignare et legare in vita vel in morte possit et valeat cuicumque seu quibuscumque personis et de eisdem disponere, prout sibi melius et utilius visum fuerit expedire - dantes et transferentes in talem et tales, quibus prefata bona per - dominum Iohannem legata, seu donata fuerint, omne ius successorium seu devolucionis, quod nobis tamquam marchioni Moravie post mortem Iohannis competere posset quovis modo, de plenitudine nostre potestatis“. S. dazu Tomaschek, Recht und Verfassung der Markgrafschaft Mähren im XV. Jahrhundert S. 37 und Člakovský a. a. O. S. 16. $\left.{ }^{2}\right)$ Man hat sich dabei gegenwärtig zu halten, dass die Hintersassen auch unter Lebenden in der Veräusserung ihrer Güter beschränkt waren, und diese, ohne deshalb besonders privilegirt zu sein, nur mit Genehmigung des Herm des Ortes, an dem sie ihren Wohnsitz hatten, verkaufen oder verschenken durften. S. das Privileg des Erzbischofs Zbynek von Prag für die Bürger seiner Stadt Kojetein v. 2. Okt. 1406 (oben S. 4 Note 1) bei den Worten: „civibus - oppidi Kogetin gratiam facientes concedimus, quod ex nunc omnes et singuli incolae - possint et valeant uniuersabona eorum mobilia et immobilia - cuique homini seu personae - vendere, legare, dare - in vita pariter ac in morte". 
suchung eines Majestätsbriefes, um diese errichten zu können, entbehrlich machte.

Das war die Gütervereinigung (spolek oder fstupek, congressio s. unio bonorum $)^{1}$ ). Der Zweck, den man dabei im Auge hatte, war der, dass die rechtlichen Folgen einer stattgehabten Abschichtung der Kinder durch den Vater oder die Mutter oder einer unter Geschwistern und andern Verwandten vorgenommenen Erbtheilung dem sonst eintretenden Heimfallsrecht gegenüber mittelst Zusammenlegung der getrennten Güter wieder aufgehoben und unschädlich gemacht wurden. Nicht minder aber bot eine solche Gütervereinigung auch den Angehörigen verschiedener, unter einander nicht verwandter Adelsfamilien das Mittel dar, um, wenn der Eine ohne Leibeserben starb, dem Andern oder seinen Nachkommen das Eigenthum und zwar das Alleineigenthum von Gütern zu verschaffen, ohne dass die verbundenen Eigenthümer genöthigt waren, schon bei Lebzeiten sich der Güter, welche sie in die Gemeinschaft einwarfen, ganz zu entäussern, während sie andererseits der Nothwendigkeit überhoben wurden, vom König einen Machtbrief zu erwirken. Wurde doch so die Errichtung einer letztwilligen Verfügung zu Gunsten dessen, dem man für den Fall des Todes Güter zuwenden wollte, überflüssig gemacht.

Das Eine wie das Andere liess sich nur im Wege einer Veräusserung unter Lebenden und nur mit Wahrung der dafür vorgeschriebenen Formen bewirken. Diese kamen hier, wo es sich um einen Gesammtbegriff von unbeweglichen und beweglichen Sachen handelte, mit den Formen überein, welche bei der Veräusserung allodialer Grundstïcke eingehalten und beobachtet werden mussten, sollte anders das Eigenthum daran gültig von dem Veräusserer auf den neuen Erwerber übergehen.

Bei den Landtagen Böhmens und Mährens, welche zugleich die Zauden oder Zuden (Landgerichte oder sog. Landrechte) bildeten, und zu denen die obersten Landesbeamten (beneficiarii) und Barone, beziehungsweise auch die Adligen

1) Cod. dipl. Mor. XII No. 577: „congressionem sive unionem, quod in volgari boemico stupek dicitur"; Brandl, Glossar. verbo spolek. 
niedern Grades zusammentraten, wurde schon im XIII. Jahrhundert die Einrichtung der Landtafeln eingeführt ${ }^{1}$ ). Seitdem konnte allodiales Grundeigenthum, mochte es dem Veräusserer durch Erbschaft zugefallen, oder von ihm erst erworben sein, nicht anders auf den Erwerber übertragen werden, denn durch Eintragung in die Landtafel ${ }^{2}$ ). Um diese zu erlangen, hatten die Kontrahenten vor den versammelten Baronen (oder in Mähren vor dem mit Führung der Landtafel beauftragten Notar) persönlich zu erscheinen und an den vom Recht ein- für allemal bestimmten Tagen im Jahr, während deren das Landrecht gehalten wurde, und die Landtafel offen stand, den von ihnen geschlossenen Kauf oder das sonstige, der Veräusserung unterliegende Rechtsgeschäft zu verlautbaren und um seine Eintragung in die Landtafel nachzusuchen ${ }^{3}$ ). Daneben aber stand es ihnen auch frei, sich an den König mit der Bitte zu wenden, dass er den von ihnen geschlossenen Vertrag nach geschehener Verlautbarung genehmige und bestätige. Entsprach dann der König dieser Bitte, so ernannte er zugleich einen Bevollmächtigten, und ertheilte ihm den Befehl, zu gehöriger Zeit und an zuständiger Stelle im Namen der Parteien die Verzeichnung des Vertrages in die Landtafel zu beantragen, und damit den Uebergang des Eigenthums an dem veräusserten Grundstück von dem Veräusserer auf den Erwerber zu bewirken ${ }^{4}$ ). In entsprechender Weise musste nun auch, wenn Adlige einander an ihren Gütern, indem sie diese zusammenwarfen, ein Recht einräumen und verschaffen wollten, der hierauf abzielende Vertrag entweder vor den Baronen, oder mit Genehmigung des Königs vor diesem errichtet oder doch verlautbart werden und hierauf seine Eintragung in die Landtafel geschehen ${ }^{5}$ ).

1) Dudik, Mährens allgemeine Geschichte IX S. $65 \mathrm{ff.}$, S. $77 \mathrm{ff}$. Randa, Die geschichtl. Entwicklung des Instituts der öffentl. Bücher in Oesterreich, Zeitschrift für Privat- und öffentl. Recht der Gegenwart. Herausgegeben von Grünhut VI. S. $81 \mathrm{ff}$. - ${ }^{2}$ ) Randa a. a. O. S. $87 \mathrm{ff}$., S. 95 ff. - 9) Maj. Carol. $59 \S 3.68 \S 4$, Karls IV. Verordn. betr. Einrichtung der Landtafel in Mähren v. 9. Febr. 1359 (Cod. dipl. Mor. IX No. 120). - ") Maj. Carol. 59 \$§ 1-2. - s) Maj. Carol. 95 § 1: ,Sicut volentibus est permissum bona et hereditates suas aliis concedere, 
Welche rechtliche Bedeutung aber hatte diese Gütervereinigung, und wie äusserten sich ihre Wirkungen? Will man sich hierüber klar werden, so ist einestheils der Zweck in's Auge zu fassen, der damit erreicht werden sollte, andererseits aber die Art und Weise, wie sie zu Stande kam, und die Form und Gestalt zu berücksichtigen, die sie annehmen musste, sollte sie zu dem gewünschten Ergebniss führen. Sieht man auf den $\mathrm{Z}_{w e e k}$, so stellt sich die Gütervereinigung als eine Erbeinigung dar. Sie soll dem einen oder dem andern Theilnehmer für den Fall, dass der eine oder der andere ohne unabgetheilte Nachkommen zu hinterlassen verstirbt, den Anfall der zusammengeworfenen Güter zu alleinigem Eigenthum sicherstellen und verschaffen: unter Umständen, wo dieser für sich und seine Erben, in Ermangelung eines ${ }^{1}$ ) gesetzlichen Erbrechts, und ohne letztwillige Verfügung des andern Theils, sonst keine Anwartschaft noch Aussicht auf ihren Erwerb haben würde.

tabularum forma servata: sic et illa bonis alterius unire et communicare nullatenus denegamus, dummodo communicantes et unientes invicem taliter bona sua, solemnitatem debitam servare non omittant, quod ea ad terrae tabulas debite apponantur". Vgl. Verordn. Karls IV. wegen Einricht, der Landtafel in Mähren v. 9. Febr. 1359 (Cod. dipl. Mor. IX No. 93) bei den Worten: „Contractus inter quoslibet homines de marchionatu Moravie quocunque donacionis, obligacionis, vendicionis, permutacionis, resignacionis, cessionis, alienacionis, divisionis, traditionis, congressionis seu unionis titulo factas, tabulis ipsis imp onere"; Urtheil oder Weisthum des Prager Landrechts v. 15. Mai 1383 (Emler, Reliquiae tabul. regn. Boh. I S. 479): „Item invenerunt pro iure, quod unio seu spolek non potest fieri alibi nisi coram domino rege de ipsius consensu, vel coram dominis baronibus in pleno iudicio".

1) Urk. des Markgrafen Jodok von Mähren betr. die Gütervereinigung zwischen der Witwe Perchta (Bertha) und ihrer Tochter Ofka und deren Eintragung in die Landtafel d. d. Prag, 14. Februar 1397. „Iodocus - marchio et dominus Moravie. Notum facimus - quod habito respectu ad diligentem peticionis instanciam, que pro parte honeste matrone Perchte, relicte quondam Waltheri de Wilhelmze et Offcze, ipsius filie, nobis humiliter existit, - indulsimus, favimus et admittimus, quod predicta Perchta cum Offka, sua filia, cum omnibus bonis ipsorum, que pronunc habent vel eas in futuro habere contigerit, nichil excluso penitus, congressionem sive unionem, quod in volgari boemico stupek dicitur, in simul licite habeant et teneant. Indulgemus et admittimus congressionem huiusmodi sive unionem de nostris con- 
Hinwiederum aber musste doch die Thatsache, dass zu dem bezeichneten $Z$ weck eine Veräusserung unter Lebenden zu geschehen hatte und mit Beobachtung von Formen zu vollziehen war, wie sie die Uebertragung des Grundeigenthums erforderte, auf Wesen und Inhalt der Gütervereinigung bestimmend einwirken. Wenn die zusammentretenden Adligen sich gegenseitig ihre Güter und ihre Fahrhabe abtraten, ergab sich daraus, wenn damit wirklich Ernst gemacht wurde, für sie ein Miteigenthum an dem so geschaffenen Gesammtgut. Dem Zweck entsprechend, dass die Güter beim Tode des einen Theilhabers, und wenn er keine erbberechtigten Verwandten hatte, dem andern allein zufielen, konnte dieses kein Miteigenthum zu Bruchtheilen, sondern es musste ein Miteigenthum zur gesammten Hand sein. Die zusammengelegten Güter wurden davon der Substanz wie dem Werthe nach ganz ergriffen, während es zu einer ziffermässigen Feststellung der Quoten, die auf die einzelnen Theilhaber oder ihre Rechtsnachfolger entfielen, um daraufhin die Auseinandersetzung und Realtheilung unter ihnen herbeizuführen, erst bei der etwaigen Wiederauflösung der Gütervereinigung $\operatorname{kam}^{1}$ ).

sensu et favore pariter nec non de gracia speciali, si quid quamcunque inter predictas Perchtam et Offkam prius mori contigerit, quod tunc eadem bona omnia et singula ad alteram, que viva remanserit, absque impediment'o quolibet devolvantur".

1) Das durch die Gütervereinigung im wahren Sinne bedingte Miteigenthum unterschied sich daher wesentlich von dem Miteigenthum, welches, ohne dass eine solche errichtet und die dafür vorgeschriebenen Formen inne gehalten und beobachtet wurden, in dem Falle eintrat, wenn zwei oder mehrere Adlige zusammen dieselben Güter für sich ankauften und als Miteigenthümer in der Landtafel eingetragen wurden. Da wurde jeder nur zu einem Bruchtheil Eigenthümer, und es fiel deshalb, wenn er ohne Leibeserben oder doch ohne erbberechtigte Verwandte zu hinterlassen verstarb, die Quote, mit der er an den erkauften Gütern betheiligt war, ohne weiteres kraft Heimfallsrechts an den König oder die königl. Kammer. S. Sentent. a iudicio terrae Bohemiae lat. (Cod. iur. Boh. II, 2 p. 33): „domini barones - invenerunt pro iure: quod ex quo alias sunt divisi, videlicet quod non habent unionem neque tabulis coram baronibus, neque ex gratia D. Regis, vel consanguineitate alias prìbuzenstvim, quod foro illo indivisi esse non possunt - , sed quod semper pars illius defuncti sine 
Man wird hiernach nicht wohl bezweifeln dürfen, dass die Gütervereinigung (unio bonorum), nachdem sie zuerst im böhmisch-mährischen Recht aufgekommen war, unter den betheiligten Grundeigenthümern eine wahre Gütergemeinschaft zu Wege brachte. Darauf weist denn auch die Sprache hin. Denn hromáždníci ${ }^{1}$ ) bezeichnet im Czechischen Personen, welche mit einander in Gütergemeinschaft stehen.

Als Gütergemeinschaft ergriff sie nicht allein die unbeweglichen und beweglichen Sachen, welche jeder der zusammengetretenen Eigenthümer im Zeitpunkte der Errichtung besass, sondern nicht minder Alles, was er späterhin, solange die Verbindung überhaupt dauerte, erwarb. Es bedurfte besonderer Abmachung, wenn gewisse Vermögensstücke, namentlich einzelne bestimmte Grundstücke, sei es von Anfang an, oder solche, die erst später dem einen oder andern Theilhaber zufielen, von dem Gesammtgut ausgenommen sein sollten ${ }^{2}$ ).

heredibus seu successoribus legitimis venire debet in ipsum D. Regem; ita quod - divisor a beneficiariis Pragensibus ad viceiudicem curiae regalis dari debet et dividere partem defuncti pro D. Rege, et residuum pro vivo vel vivis" (1383 2. Oct.) vgl. mit: Inventiones baronum (das. II, 2 p. 284): „Quatuor emunt simul, et forum (hier gleichbedeutend mit Handel oder Kauf) stat in tabulis, - qui ex eis moritur, pars eius cadit in regem; nisi esset privuzenstvie vel unio coram baronibus vel per regem data".

Anders bei der Gütervereinigung. Da musste immer erst deren Auflösung herbeigeführt werden, ehe und bevor festzustellen war, zu welchem Verhältuiss ein jeder der verbundenen Miteigenthümer an den zusammengeworfenen Gütern antheilsberechtigt war, um danach weiter die Realtheilung in's Werk zu setzen. Eine solche Auflösung der Gütervereinigung behufs Auseinandersetzung der Theilhaber sah die Maj. Car. $95 \$ 4$ für den Fall vor, dass einer der Verbundenen ein Verbrechen beging, welches die Strafe der Gütereinziehung nach sich zog, indem sie bestimmte: ,si hereditas alterius unitorum in bonis propter crimina per eum forte commissa veniant confiscanda: tunc aequali facta divisione bonorum omnium simul unitorum, pars sua ad regiam cameram devolvatur, parte reliqua penes alium consocium illaesa et solida remanente".

1) S. Brandl. Glossar. beim Worte hromáždníci. - 2) Man vgl. z. B. Emler, Reliquiae tabul. II S. 110. 1414 2. Oct.: „Anna relicta olim Swasskonis de Miliczina, Margaretha et Dorothea ibidem flie eius et Iohannes de Bukowa p.s c. dominis baronibus in pleno iudicio 
$\mathrm{Ob}$ und wie lange die Gütergemeinschaft zugleich eine ungetrennte Gewere der Güter, zum wenigstens der zusammengeworfenen Liegensehaften auf Seiten der congressores oder unitores, wie die lateinisch abgefassten Quellen und Urkunden die verbundenen Adligen nannten, mit sich brachte und erforderte, wird sich kaum feststellen lassen.

Eine Urkunde vom Jahre $1325^{1}$ ) zeigt, dass, ungeachtet bestehender Gütervereinigung, der einzelne Theilhaber sich im alleinigen Besitz der eingeworfenen Güter behaupten konnte und so thatsächlich in der Lage war, darüber eigenmächtig zu verfügen, um sie einem Andern eigenthümlich zu überlassen und abzutreten, der selbst kein antheilsberechtigter congressor war. Freilich geschah eine solche Veräusserung unrechtmässig. Die übrigen Theilhaber waren befugt, die hinter ihrem Rücken und ohne ihre Zustimmung stattgefundene Veräusserung anzufechten und rückgängig zu machen, indem sie sich der betreffenden Güter unterwanden ${ }^{2}$ ).

et b. P., quod hereditatibus ipsorum, videlicet ipsa Anna hereditate sua dotali obligata, Margaretha et Dorothea hereditatibus ipsorum hereditariis in Thomiczkach, curiis rusticalibus cum censu, cum villa integra, agris, pratis, riuis, piscinis - et aliis hereditatibus eorum et rebus mobilibus omnibus habitis et habendis et ipse Iohannes hereditate sua in Przebniczich curiis rusticalibus cum censu, in Mladussewie curiis rusticalibus cum censu - et aliis hereditatibus suis et rebus mobilibus habitis et habendis vniverunt se simul ita quod facti sunt veri vnitores et hromazdnikones omnium premissorum" mit daselbst I S. 563, 1396, 29. Maii: „Margaretha relicta olim Jesskonis dicti Buch de Swietze protestata est coram b. P. et dominis baronibus, quod super hereditates suas in Tatimem, curia arature, in Widowli toto, quidquid ibi habet, in Sabeniczich toto - et alias habitis vel habendis cum agris, pratis, siluis, piscinis - exclus is hereditatibus in Wrbiczi, quas ibi habet quia easdem pro se reservat, Buskonem de Zzenberg et Georgium de Diwicz in veram suscepit unionem" -

1) Cod. dipl. Mor. XII, No. 94. - ${ }^{2}$ ) Man vgl. die in der vorigen Note angeführte Urkunde v. J. 1325, Albert von Sternberg schenkt seinem (von ihm abgetheilten) Bruder Stephan sein Schloss Swinkow mit allem unbeweglichen und beweglichen Zubehör, indem er damit nur die Auflage verbindet, er solle seiner Schwester Elisabeth 500 Mk. mährischer Groschen zur Heimsteuer aus den empfangenen Gütern auszahlen. Dann heisst es: „Si vero aliquis ex nostris congressoribus, vulgariter stupkuov - Stephanum aut suos heredes de eodem castro 
Und dieses Anfechtungsrecht war, was den Gegenstand der Veräusserung angeht, ein umfassenderes als das gleiche Recht der wartberechtigten Kinder, bei Veräusserungen, die der Vater, ohne sie zu fragen, vornahm. Denn, während der Vater in der Veräusserungsfreiheit nur insoweit eingeschränkt war, als er Güter, welche er ererbt hatte, - den Fall der echten Noth ausgenommen - nicht ohne Zustimmung seiner Kinder, sofern er diese nicht abgefunden hatte, veräussern durfte, erstreckte sich das Recht der congressores auf alle Liegenschaften, welche Gegenstand einer Gütervereinigung waren. Es machte da keinen Unterschied, ob der eine oder

et ceteris - auderet impetere quovis modo aut impugnare pinguius ius ad eadem bona habere volentes: extunc - Stephano decem millia marcarum grossorum denariorum pragensium moravici numeri et pagamenti, imo et assignatis pecuniis predictis eidem domino suprafato aut eius heredibus - licite se intromittere possunt de bonis -." Wenn hier den congressores, für den Fall, dass sie die stattgehabte Güterschenkung und Veräusserung anfechten und sich der Güter, welche Gegenstand derselben waren, unterwinden, die Leistung einer Entschädigung an den aus dem Besitz verdrängten Stephanus zur Pflicht gemacht wird, ist das, wie mir scheint, nur zu erklären, wenn man folgende Erwägung anstellt. An sich konnte bei bestehender Gütervereinigung, solange der Veräusserer oder seine Erben noch lebten, die Anfechtung der von ihm widerrechtlich vorgenommenen Veräusserung durch seine congressores nur die Wiederherstellung des früheren $\mathrm{Zu}$ standes und die Zurückführung der Güter in das Gesammtgut zur Folge haben. Denn mit der Veräusserung, mochte sie auch unrechtmässig geschehen, verwirkte der Veräusserer selbst sein Miteigenthum am Gesammtgute noch nicht. Wohl aber stand es ihm frei hierauf zu verzichten: entweder schlechthin oder, indem er das Aufgeben der ihm aus der Gütervereinigung erwachsenen Rechte von einer ihm oder seinem Nachfolger im Besitz der unrechtmässig veräusserten Güter seitens der congressores zu leistenden Geldentschädigung abhängig machte.

S. ferner Emler, Reliquiae tabul. I S. 564: „Benessius de Dubec et de Libiessicz defendit contra permutacionem, ubi Alsso filius Henrici dicti Skopek de Dubec commutauit hereditatem in Rasst Parvo pro hereditatibus in Welenez cum domino Procopio abbate monasterii S. Karoli - prout hoc idem in terre tabulis continetur, dicens, quod ipse Alsso dictus hereditates permutare non potuit ex eo, quod ipse Benessius cum patre dicti Alssonis Henrico super dictis hereditatibus fuit verus unitor. Docere vult tabulis terre, quando ei domini barones terminum assignabunt". 
der andere der mehreren verbundenen Adligen,"der sie ohne Zustimmung des andern veräusserte, solche erkauft oder sonstwie später erworben, oder schon von seinen Eltern oder Grosseltern ererbt hatte, und ebensowenig kam, da ja die Gütervereinigung auch den künftigen Erwerb ergriff, etwas darauf an, ob es sich um Güter handelte, die der Veräusserer schon bei deren Errichtung besass, oder ob diese ihm erst hinterher zufielen und so Theil des Gesammtgutes wurden.

In allen Fällen einer unrechtmässigen Veräusserung, mochte solche vom Nichteigenthümer oder von dem in der Verfügung eingeschränkten Eigenthümer ausgehen, hatte der, welcher aus einem oder dem andern Grunde sich für berechtigt halten durfte, wegen Mangels der Verfügungsberechtigung auf Seiten des frühern Besitzers dem Erwerber die ihm veräusserten Güter streitig zu machen, die Klage auf Wiederaufhebung der Veräusserung und Herausgabe des Besitzes innerhalb der allgemeinen, dem böhmischmährischen Rechte eigenthümlichen Verjährungsfrist von 3 Jahren 18 Wochen ${ }^{1}$ ) zu erheben. Andernfalls wurde die Veräusserung eine unwiderrufliche. Der dadurch Benachtheiligte konnte den Erwerber nicht mehr aus dem Besitz verdrängen, noch sich der Güter, wegen deren ihm ein Recht zustand, unterwinden.

Seit Einführung der Landtafeln in die Rechtsverfassung Böhmens und Mährens nahm die Anfechtungsklage die Form

1) S. über diese Frist und ihre vermuthliche Entstehung Randa in der Zeitschrift für Privat- u. öffentl. R. VI S. 96 Note 42. Sie lief von Zeit der erfolgten Inscription an. Wenn die Maj. Car. Art. 60 \$§ 3-7 den Lauf der Frist erst von der erfolgten Einweisung in den Besitz der ihm abgetretenen Güter, oder genauer gesagt, von dem Zeitpunkt an beginnen lassen wollte, nachdem die geschehene Veräusserung und Eintragung des Kaufs u. s. w. in die Landtafel zum dritten Mal an verschiedenen, dem betreffenden Gute nahe gelegenen Marktorten offentlich verkündet worden war, so blieben diese Bestimmungen anscheinend unpraktisch. Die späteren Quellen, soweit sie mir bekannt geworden sind, wissen davon nichts mehr. Ich nehme deshalb mit Randa a. a. 0 . S. 95 an, dass der Zeitpunkt der Inskription der für den Anfang des Laufes der Verjährungsfrist massgebende war oder es doch später wurde. S. auch Iura et const. regnante Wladislao in der lat. Uebersetzung des Dubravo de Dubrava p. 126 No. 224. 
eines Widerspruchs (odpor. ${ }^{1}$ ) an, gerichtet gegen die ungerechtfertigte Einlage (Eintragung) des Rechtsgeschäfts, durch welches der Veräusserer sich seines vermeintlichen oder wirklichen, wenngleich beschränkten Eigenthums zu Gunsten eines andern, als des neuen Erwerbers des Gutes oder der Güter begeben hatte. Weil der Eintragung keine bloss processualische (die Thatsache des Eigenthumsüberganges beweisende), sondern eine materiellrechtliche, Eigenthum schaffende Bedeutung beiwohnte ${ }^{2}$ ), galt der Erwerber, mochte immerhin sein Erwerb sich in unrechtmässiger Weise vollzogen haben, zunächst und dem formalen Recht gegenüber als Eigenthümer. Daher hatte denn der zur Anfechtung einer stattgehabten Veräusserung Berechtigte mit der innerhalb der bezeichneten Frist von 3 Jahren und 18 Monaten zu erhebenden Odpor-Klage nicht sowohl die Ungültigkeit des der Veräusserung unterliegenden Kaufes oder andern Rechtsgeschäfts zu behaupten, sondern auch der darauf hin in der Landtafel bewirkten Eintragung zu widersprechen und vom Richter zu begehren, dass er diese für kraftlos erkläre und wieder aufhebe.

Auf die Gütervereinigung angewandt stützte sich dieses Begehren in der Thatsache, dass die Veräusserung an den beklagten Besitzer und die Eintragung seines Eigenthums in der Landtafel um deshalb ungültig und für nichtig zu erklären sei, weil sie in Widerspruch stehe mit einer früher errichteten und in der Landtafel verzeichneten Gütervereinigung, und das streitige Gut oder die streitigen Güter in diese eingeworfen und mit den Gütern des Klägers zu einer gemeinschaftlichen Masse zusammengelegt worden seien $^{3}$ ).

Dahingegen schieden, wenn diese Anfechtung entweder ganz unterblieb, oder nicht rechtzeitig innerhalb der Verjährungsfrist von 3 Jahren 18 Monaten geltend gemacht wurde, die Güter, welche dem dritten Erwerber ohne Zustimmung der congressores von einem der Theilhaber bei

1) S. Brandl, Glossar. beim Worte odpor (odpora). — ${ }^{2}$ ) Randa a. a. O. S. 95. - ${ }^{3}$ ) Emler, Reliquiae tab. I S. 564 (oben S. 25 Note 1). 
der Gütervereinigung eigenthümlich überlassen waren, aus dem Gesammtgute aus ${ }^{1}$ ).

War es nicht nothwendig, dass die mit ihren Gütern zusammengetretenen Adligen diese in gemeinsamer und ungetheilter Gewere behielten, so stellt dahingegen die Majestas Carolina ${ }^{2}$ ) ein anderes Erforderniss als ein wesentliches und nothwendiges hin, wenn anders die Gütervereinigung als solche anerkannt und rechtlich behandelt werden soll. Es muss dabei eine Gemeinschaft stattfinden auf Gedeih und Verderb, so dass jeder Gewinn, den einer der congressores macht, dem Gesammtgut zuwächst, während hinwiederum jeder Verlust dieses und alle daran Betheiligten trifft. Das schloss eine Theilung der Nutzungen unter die einzelnen verbundenen Grundbesitzer nicht aus, noch verbot es, dass jeder von ihnen die von ihm in die Gemeinschaft eingebrachten Güter selbst bewirthschaftete und verwaltete und die in der Wirthschaft nöthig werdenden Ausgaben bestritt. Wohl aber war er verpflichtet, das, was er etwa mehr erzielte, als die auf seinen Theil fallenden reinen Einkünfte, nach Verhältniss der Antheile eines jeden mit den übrigen Genossen $\mathrm{zu}$ theilen, wohingegen Verluste, die er ohne seine Schuld erlitt, auf alle zu übertragen und ihm verhältnissmässig zu erstatten waren. Ohne eine solche Gemeinschaft in Gewinn und Verlust (Vortheil und Schaden) wollte Karl IV. der Gütervereinigung die Anerkennung selbst dann versagen, wenn mehrere, angeblich verbundene Adlige am selben Orte

1) Iura et constitutiones regni Boemiae regnante Wladislao a. 1500 edit. a Roderico Dubravo de Dubrava latinitate donatae (typis vulgatae cura Franc. Palacký) p. 126 No. 224: „Pro iure constitutum est: qui se univerunt bonis, si alter alterius non contradicit venditioni, oppignorationi et dotis proscripto permittitque silentio suo tres annos et XVIII ebdomadas preterire, cum pateret aditus tabularum etiam si iura suum progressum non haberent, tunc talis unio silentio perimitur, et quiuis quicquid possideret talium bonorum, debet frui illis bonis, et apud illum illa remanere debent, tanquam bona hereditaria“. — 2) Maj. Car. $95 \$ 2$ : „Si uniti in bonis eorum separati habitant, sumptusque quisque separatos faciat et in diversis castris vel locis aliis: non propterea intelligatur unio fraudulenta vel simulata, dummodo probare possint, si necesse fuerit, per testes idoneos coram baronibus, quod alias in damnis et emolumentis omnibus uniti participant et contribuunt". 
oder Dorfe zusammen lebten, während ein jeder seine Güter nach wie vor selbstständig und allein bewirthschaftete. Es sollte dann angenommen werden, die Kontrahenten hätten sich nur zum Schein verbunden, in der arglistigen Absicht, um das Heimfallsrecht des Königs illusorisch zu machen ${ }^{1}$ ).

Wie aber nicht alle in dem Gesetzentwurfe enthaltenen Bestimmungen durch das spätere Gewohnheitsrecht die Kraft verbindlicher Normen bekamen, so wurde auch der darin aufgestellte Satz, dass die Gütervereinigung eine Gemeinschaft sein müsse in Gedeih und Verderb, nicht zum massgebenden Grundsatz. Man setzte sich darüber hinweg. Es wurde gestattet, . dass einer von zwei Brüdern die sämmtlichen in die besagte Gütervereinigung eingeworfenen Güter in seine Gewere und unter seine alleinige Verwaltung nahm und dem andern Bruder dafür, solange dieser lebte, eine bestimmte Rente alljährlich zu zahlen versprach. Dieser behielt so an den Gütern selbst, ohne an Gewinn und Verlust bei deren Bewirthschaftung ferner betheiligt zu sein, eine blosse Zinsgewere. Immerhin blieb ihm daneben noch die Aussicht, ihren Besitz mit allem Zubehör zu alleinigem Eigenthum zu erlangen, wenn er den Bruder überlebte und bei dessen Tode keine Nachkommen vorhanden waren. Dahingegen wurde dieser als der Rentenschuldner, und ebenso sein Erbe von der Rentenschuld frei, sobald der Bruder, dem sie zu zahlen war, verstarb ${ }^{2}$ ).

1) Maj. Car. $95 \S 3:$ :In bonis se dicentes unitos, licet in uno eodemque loco vel villa residentes seu larem foventes, separati sunt potius et divisi, nec unionem alliganti credetur, nisi testibus idoneis plene probaverit, quod unio ipsorum non obstante divisione vel separatione praedicta (cf. $\$ 2$ pag. 28 Note 2 ), sine omni figmento, simulatione et fraude procedit". - 2) Emler, Reliquiae tabul. I p. 436, 1369, 1. Sept.: „Marquardus de Porzessin p. e. quod 20 sex. gr. prag. census annui et nudi - tenetur et debet solvere et sui heredes domino Iohanni fratri suo germano ibidem de Porzessin vnitori suo - ad tempora vite ipsius domini Iohannis tantum, et post mortem ipsius domini Iohannis idem census ad usum Marquardi et suos heredes devolvi debet, et a solucione liberi et soluti esse debent; mortuo autem ipso Marquardo vna cum heredibus suis extunc omnes hereditates cum omnibus rebus mobilibus et immobilibus ipsius Marquardi ad dictum dominum Iohannem devolvi debet, tamquam ad verum vnitorem, et que unio in tabulis terrae plenius continetur." 
Man blieb dabei noch nicht stehen. Man liess auch die Errichtung und Eintragung einer Gütervereinigung in der Landtafel mit dem Vorbehalt zu, dass es einem der betheiligten Grundbesitzer freigestellt blieb, die von ihm eingeworfenen Güter, solange er lebte, zu verkaufen oder zu verpfänden, ohne dazu der Einwilligung der übrigen congressores oder unitores zu bedürfen ${ }^{1}$ ). Eine in dieser Weise eingegangene Gütervereinigung hinderte den Beitretenden nur noch an letztwilligen Verfügungen, soweit von solchen, solange es dazu der Erlangung eines Majestätsbriefes bedurfte, überhaupt die Rede sein konnte, und an der Vornahme von Schenkungen unter Lebenden. Sie fiel so inhaltlich und den Wirkungen nach nahezu mit einem Erbvertrage und zwar mit einer Erbeinigung oder Erbverbrüderung zusammen. Der Umstand, dass sie von den zusammengetretenen Adligen in den Formen errichtet war, wie sie sonst bei der Veräusserung und Eigenthumsübertragung von Grundstücken beobachtet wurden, blieb ausser Betracht, oder man legte darauf doch nicht mehr das Gewicht wie früher.

Nicht weniger galt es in diesem späteren Stadium der rechtsgeschichtlichen Entwicklung für erlaubt, eine Gütervereinigung mit Beschränkung auf die Person des einen oder des andern der Theilnehmer zu errichten: dergestalt, dass, wenn dieser vor andern seinen congressores (oder unitores) starb, die Kinder, welche er etwa hatte, von jedem Antheil am Gesammtgute ausgeschlossen blieben ${ }^{2}$ ). Den Letzteren er-

1) Emler, Reliquiae tab. II p. 37, 1407, 20. Maii: „Mathias de Kostomlat et de Vgezd p. e. c. b. P. et coram baronibus in pleno iudicio, quod super hereditates suas in Catynyewssy super curia cum duabus agriculturis - Nicolaum de Lomnycze, Cundolt pueros Wenceslai de Kostomlat fratris sui, quos habet et Ieronimum de Costomlat filium Cunssonis in veram suscepit unionem, ita quod facti sunt cum eo vero unitores seu hromáždnici omnium premissorum, cum ea condicione, quod prefatus Mathias quidquid voluerit in vita sua poterit de dictis hereditatibus vendere et obligare absque ipsorum consensu". - ${ }^{2}$ ) Emler, Reliquiae tab. I p. 478, 1383, 15. Febr.: „Fricz de Liblicz p. e. coram - Wenceslao Romanorum et Boemie rege et c. b. P. quod super hereditates in Liblicz, in Bissicz, in Nedomicz et Bukol - - - et alias omnes hereditates suas habitas vel haben- 
öffnete sich in Folge dessen die Aussicht auf den Erwerb der zusammengelegten Güter nur dann, wenn ihr Vater den andern congressor, der sie von der Union ausgeschlossen hatte, überlebte und so in den Stand gesetzt wurde, die ihm angefallenen Güter oder Antheile an diesen auf sie weiter $\mathrm{zu}$ vererben.

Auch diese Modalität liess sich nur rechtfertigen, wenn man die Gütervereinigung mehr unter dem Gesichtspunkt einer Erbeinigung, betrachtete, denn als eine unter Lebenden vorgenommene Veräusserung. Solange man an dem Charakter einer Veräusserung festhielt, konnte wohl bei der Errichtung der Gütervereinigung ausgemacht werden, sie solle, wenn einer der congressores vor den übrigen sterben würde, wieder aufgelöst werden, und die zusammengelegten Güter in das alleinige und ausschliessliche Eigenthum derjenigen zurückkehren, die oder deren Vorfahren sie in die Gemeinschaft eingebracht hatten. Nicht aber ging es an, dass man von Anfang an bestimmte, es sollten die Kinder des einen oder des andern Betheiligten in die Gütervereinigung gar nicht mit aufgenommen sein. Rückten diese doch sonst ohne weiteres in den mit dem Tode ihres Vaters ledig gewordenen Antheil am Gesammtgute ein. Ihre Nichtaufnahme war nur denkbar und möglich, wenn die Gütervereinigung sich überhaupt erst geltend machte in dem Falle, dass der eine oder der andere der vereinigten adligen Besitzer früher als der andere starb.

Aus alle dem erhellt, dass das Institut der Gütervereinigung im Fortgange der Zeit Wesen und Bedeutung einer Gütergemeinschaft, welche sie ursprünglich gehabt hatte, mehr und mehr abstreifte. Denn, wenn auch vielleicht nicht

das cum rebus mobilibus - Iohannem de Liblicz flium Cunssonis filiastrum suum, exclusis suis pueris, in veram suscepit unionem".

Das. II p. 98, 1413, 21. Mart.: „Arnestus Flassk a de Rychenburg p. e. c. dom. bar. in iudicio et b. P. quod super omnes hereditates suas videlicet in Rychenburg castrum, Skutecz oppidum - ac super totum, quidquid habet vel habebit in futurum, Czenkonem de Wesele et de Wartemberg, Strzezkonem de Colodieg et Wenceslaum Prczucher de Pabienicz absque ipsorum liberis in reram suscepit vnionem, ita quod facti sunt cum eo veri unitores seu společ nisi omnium premissorum". 
immer und nicht überall, konnte ihr doch jedesfalls unter gewissen Umständen und auf Grund getroffener besonderer Abmachung und Vereinbarung gegen Ausgang des Mittelalters eine Form und Gestalt gegeben werden, welche sich von der eines Erbvertrages und einer Erbeinigung und Erbverbrüderung unter mehreren Personen, die lediglich den Willen und die Absicht hatten, sich für den Fall des Todes ein gegenseitiges Erbrecht zu verschaffen, nur noch wenig oder gar nicht unterschied.

IV.

Als in der zweiten Hälfte des XIII. Jahrhunderts das Lehnswesen Eingang fand, wurde man in Böhmen und Mähren alsbald mit dem deutschen Lehnrecht, insonders mit dem Inhalt der deutschen Lehnrechtsbücher bekannt ${ }^{1}$ ), nicht aber gelangten darum etwa sofort auch alle Vorschriften zur Anerkennung und Geltung, welche das deutsche Lehnswesen regelten. Zwar der Grundsatz, dass Lehne innerhalb der vom Erstbeliehenen ausgehenden Nachkommenschaft immer nur in gerader Linie vom Vater auf den Sohn, nicht in der Seitenlinie auf den Bruder des zuletzt verstorbenen Lehnsbesitzers vererben, wurde auch in Böhmen und Mähren vom ersten Aufkommen des Lehnswesens an massgebend ${ }^{2}$ ). Und

1) Das mährische Lehnrecht des XIV. Jahrhunderts : „prawa manska“, war nichts anderes, denn eine wörtliche Uebersetzung des Lehnrechts des Schwabenspiegels. S. Rössler, Einleitung zu seiner Ausgabe der Stadtrechte von Brünn, S. XXXIX. - $\left.{ }^{2}\right)$ Brüder, welche die väterlichen Lehngïter unter sich theilten, vermochten daher ein wechselseitiges Erbrecht in diese nur zu erlangen, wenn sie deshalb vom Lehnsherrn besonders privilegirt und begnadigt wurden, der dann zugleich auf Ausïbung seines Heimfallsrechts für den Fall verzichtete, dass einer von ihnen bei seinem Tode keine lehnsfähigen Nachkommen haben würde. Urk. des Markgrafen Karl von Mähren (nachherigen Königs und Kaisers Karl IV.) vom 31. Mai 1343 für die Brüder Smil, Ceň̌k und deren Neffen Johann von Lichtenburg: „Nos Karolus Marchio Moravie - Smyloni, Tschenkoni - atque Iohanni filio fratris ipsorum quondam Heinrici - de speciali gratia indulgemus, ut bona ipsorum videlicet castra Velthau et Czornstein -, que iure homagiali tenent et possident a nobis in feodum - in tres partes dividant, et ipsos - amplioribus beneficiis decrevimus premiando de nostra munificentia - admittentes, quod pars cuiuslibet eorum antedictorum bo- 
ebenso war anscheinend der Lehnsherr, wenn der Lehnsmann mit Hinterlassung mehrerer Söhne starb, berechtigt, nur einen von diesen als Lehnsmann anzunehmen und in den Besitz des Lehngutes kommen zu lassen, dahingegen einer 'Theilung unter die mehreren Söhne zu widersprechen ${ }^{1}$ ).

Anders aber verhielt es sich mit der Möglichkeit einer Veräusserung des Lehns durch dessen jeweiligen Besitzer. Während das deutsche Lehnrecht von Alters her dem Lehnsmann eine Veräusserung des Lehns nicht oder doch nur dann erlaubte, wenn sie mit Wissen und Willen des Herrn geschah, kannte man in Böhmen und Mähren in den ersten Jahrzehnten nach Einführung des Lehnswesens ein Verbot der Lehnsveräusserung nicht.

Eine Ausnahme machte in dieser Hinsicht nur das geistliche Fürstenthum Olmütz, in welchem der Bischof mit Unterordnung unter die Oberhoheit des Königs von Böhmen, beziehungsweise des Markgrafen von Mähren eine landes- und lehnsherrliche Gewalt ausübte. Das Recht der Vasallen der magdeburger Kirche, welches Bischof Bruno seit 1251 seinen zahlreichen an deutsche und czechische Ritter und Edle ertheilten Verleihungen von Lehnen zu Grunde legte, entsprach nicht in allen Stücken dem Begriff eines wahren Lehnrechts. Es vereinigte in sich Lehn - und dienstrechtliche Elemente, die einestheils dem sächsischen Lehnrecht, anderntheils dem Dienstrecht der Ministerialen der bischöflichen magdeburger Kirche entlehnt wurden ${ }^{2}$ ). Für die Frage aber, ob der Lehnsmann befugt war, sein Lehngut zu veräussern und deren Beantwortung und Entscheidung gab im Geltungsbereiche dieses Rechts von Anfang an das deutsche und zwar das sächsische Lehnrecht die Richtschnur ab. Dem-

norum - per mortem possessoris eiusdem, non obstantibus iuribus nobis in ipsis bonis occasione homagii vel iuris terre nostre Moravie competentibus vel in futurum competere potentibus, quibus nostro ac successorum nostrorum nomine renunciamus expresse, ad alios vel alium superstites et vivos vel superstites libere revertatur". Vgl. damit Urk. d. Bischofs Theoderich v. Olmütz v. J. 1297 für Herbord gen. Traberger von Fullstein (Cod. dipl. Mor. V No. 62).

1) S. die vorige Note. - $\left.{ }^{2}\right)$ S. meine Abhandlung in dieser Zeitschrift XIV. Bd. (Germ. Abthl.) S. $63 \mathrm{ff}$.

Zeitschrift für Rechtsgeschichte. XX. Germ. Abth. 
nach konnten die zu magdeburger Vasallenrecht beliehenen Lehnsmannen nur dann ihre Lehnsgüter gültig veräussern, wenn sie vom Olmützer Bischof als ihrem Lehnsherm auf vorgetragene Bitte die Genéhmigung erhalten hatten ${ }^{1}$ ).

Dahingegen behielten die vom Könige von Böhmen oder vom Markgrafen von Mähren belehnten Vasallen und nicht minder die, welche einen Dynasten zu ihrem Lehnsherrn hatten, noch längere Zeit hindurch freie Hand in der Verfügung über ihre Lehne. Erst das in die Form eines Urtheils seines Lehnshofes eingekleidete Gesetz Karls IV. vom 12. December 1360 sprach den böhmischen und mährischen Vasallen jedwede Befugniss ab, über den Gegenstand des Lehns ganz oder zum Theil ohne Wissen und Willen des Lehnsherrn unter Lebenden oder von Todes wegen zu verfügen ${ }^{2}$ ).

Neben mehreren anderen und verschiedenen Weisen, wie ein Lehnsmann über den Lehnsgegenstand verfügen konnte, wird in diesem Gesetz auch die Möglichkeit vorgesehen, dass er sein Gut oder seine Güter mit dem Lehn

1) Hieran änderte auch das Privileg nichts, mit dem der Bischof Theoderich (Dietrich), der Nachfolger Brunos, im J. 1281 seine Vasallen begnadigte (Cod. dipl. Mor. IV No. 185). Denn wenn ihnen damit auch die Zusicherung ertheilt ward, es solle ihnen, sofern sie wegen Alters, Krankheit oder aus Armuth ihren Lehnspflichten nicht mehr nachkommen könnten, die Veräusserung ihrer Lehne gestattet sein, so wurde daran doch die Bedingung geknüpft, dass ein jeder von ihnen im einzelnen Falle dazu die lehnsherrliche Zustimmung vom Bischofe einhole. Eine völlige Veräusserungsfreiheit erlangten sie sonach nicht. Der Lehnsherr versprach nur, wenn die bezeichneten Umstände erwiesenermassen eintreten würden, seine Zustimmung zu der beabsichtigten Veräusserung nicht zu versagen. - ${ }^{2}$ ) Cod. dipl. Mor. IX No. 206. Den um die Person des Kaisers und unter seinem Vorsitz in Nürnberg zum Lehnshofe versammelten geistlichen und weltlichen Fürsten und Baronen wird die Frage zur Beantwortung und Entscheidung vorgelegt: „Ob einem Lehenmann erlaubet sei, daz er sein lehengut gar oder eines teiles geben, verkauffen, schaffen, bescheiden, aufgeben oder einen mit yemanden muge an des Lehenherren gunst vnd willen". Darauf ergeht das Urtheil: „daz ein lehenman sein lehengut gar oder eins teils mit nichte muge yemanden geben, verkauffen, schaffen, bescheiden oder vfgeben, noch daz mit yemanden einen oder zesampue legen, noch keine empfremdung tun, ez sei denne mit dez lehenherren guten wizzentlichen willen". 
eines andern zusammenlegt und vereinigt. Das soll ebenso wie jede andere Verfügung über die Lehnssubstanz nicht anders denn mit Wissen und Zustimmung des Lehnsherrn geschehen dürfen.

Im Landrecht fiel, wie wir sahen, die Gütervereinigung unter den Begriff einer Lehnsveräusserung unter Lebenden. Man wird nicht zweifeln dürfen, dass das böhmisch-mährische Lehnrecht von dem gleichen Gesichtspunkte die Gütervereinigung ebenfalls als eine, wenngleich besondere Art der Lehnsveräusserung, welche die betheiligten Personen unter einander vornahmen, angesehen und behandelt wissen wollte.

Das Lehnsgesetz von 1360 bedient sich, um eine letztwillige Verfügung über das Lehn oder eine Vergabung von Todes wegen zu bezeichnen, der Worte: ,schaffen, bescheiden" beziehungsweise, ,vfgeben" und unterscheidet hiervon das Einen oder Zusammenlegen mehrerer Lehngüter zu Einem Lehnsgegenstand durch zwei oder mehrere Vasallen ${ }^{1}$ ). Will man hierauf noch kein Gewicht legen, so ergiebt sich doch die Auffassung der Gütervereinigung bei Lehnen als eine unter Lebenden stattfindende Veräusserung aus der Erwägung, dass diese nur so sich auf den Boden des in die einheimische Rechtsbildung recipirten deutschen Lehnrechts stellen und damit in Einklang bringen liess. Dem deutschen Lehnrecht war eine der böhmisch-mährischen Gütervereinigung gleiche oder analoge Einrichtung fremd. Der Zweck, einen Ersatz für ein fehlendes gesetzliches oder in letztwilliger Verfügung beruhendes Erbrecht zu schaffen, um einem Heimfall des Lehns an den Herrn vorzubeugen, wenn der Vasall ohne lehnsfähige Nachkommen zu hinterlassen starb, liess sich da nur durch eine Gesammtbelehnung erreichen, welche der Herr mehreren Brüdern oder Vettern oder wohl auch den Mitgliedern von Familien ertheilte, welche nicht mit einander verwandt waren. Als ein Akt der Belehnung konnte diese nur vom Herrn selbst ausgehen, mochte dieser dazu die Initiative ergreifen oder damit einen Wunsch erfüllen, den ihm einer oder der andere seiner Lehnsmannen ausgesprochen hatte.

1) S. vorige Note. 
Anders bei der Gütervereinigung. Da wurde ebenso wie bei dem Verkaufe des Lehns oder einem sonstigen auf dessen Veräusserung in andere Hand abzielenden Vertrage die von den betheiligten Personen ohne seine Mitwirkung getroffene Abmachung dem Herrn entgegengebracht und vorgelegt, und dieser hatte sich nur darüber schlüssig zu machen und zu erklären, ob er den Vertrag gutheissen und genehmigen und so der mit dem Lehn vorzunehmenden Veränderung die gleiche Kraft geben wollte oder nicht. Dieses verglichen mit der Ertheilung der Gesammtbelehnung einfachere und für alle in Frage kommenden Lehnspersonen bequemere Verfahren musste die Gütervereinigung und ihre Herstellung empfehlen, zumal da es sich dabei um eine im Lande bekannte, und gewohnte Einrichtung handelte. Es kam hinzu, dass man im XIV. Jahrhundert, als man in Böhmen und Mähren anfing davon bei Lehnen Gebrauch zu machen, die deutsche Gesammtbelehnung schon nicht mehr ihre ursprüngliche strenge Form und Gestalt bewahrt hatte. Sie verlangte nicht mehr, wie früher, dass die Gesammthänder, sollte nicht die gesammte Hand aufgelöst werden und das darin beruhende und mit ihr vornehmlich bezweckte Anwachsungsrecht der Kollateralen wegfallen, die Lehngüter in ungetrennter und ungetheilter Gewere behielten ${ }^{1}$ ). Ebensowenig aber war bei der Gütervereinigung eine ungetheilte Gewere der zusammengelegten Güter damals noch nothwendig. Das darf man, wie für das Landrecht, so für das Lehnrecht annehmen und behaupten. Warum sollten nun die Vasallen, statt beim Herrn um eine Gesammtbelehnung nachzusuchen, es nicht vorziehen, unter sich eine Gütervereinigung zu schliessen, welche dann der Herr auf deshalb gestellte Bitte nur zu genehmigen brauchte? Wurde doch so die Gesammtbelehnung erübrigt und die Weitläufigkeiten umgangen, die trotz mancher Erleichterung in der Form, auch in Böhmen und Mähren damit verknüpft sein mochten. Denn in den Wirkungen kamen beide, Gesammtbelehnung und Gütervereinigung auf dasselbe hinaus und dienten dem gleichen Zwecke.

1) Schröder, Deutsche Rechtsgeschichte (dritte Aufl) S. 410. 
Immerhin ist es, nach den vorhandenen Urkunden zu schliessen, die davon nichts melden, im geistlichen Fürstenthum Olmütz als dem engeren Geltungsbereiche des sg. magdeburger Vasallenrechts zu einer Anwendung der Gütervereinigung auf Lehne zunächst nicht gekommen. Auch einer Gesammtbelehnung durch den Bischof als den Lehnsherrn an seine Ritter und Edlen wurde dort nur selten stattgegeben ${ }^{1}$ ). Dahingegen machten die Olmützer Vasallen seit den letzten Jahrzehnten des XIV. Jahrhunderts von der Gütervereinigung in Bezug auf ihre Lehne verhältnissmässig oft, ja man darf sagen auffallend häufig Gebrauch, ohne dabei auf Schwierigkeiten zu stossen. Vielmehr genehmigte der Bischof, anscheinend anstandslos, die ihm vorgelegten auf die Zusammenlegung von Lehngütern gerichteten Verträge ${ }^{2}$ ).

Sieht man auf den Gegenstand dieser lehnrechtlichen Gütervereinigung, so war diese ihrem Umfange nach eine

1) Unter den zahlreichen im Cod. dipl. Mor. enthaltenen, die Lehne der Olmützer Vasallen betreffenden Urkunden sind mir im Ganzen nur 2 aufgestossen, in welchen von einer Belehnung zur gesammten Hand die Rede ist. Im Jahr 1280 stellen die Brüder Dietrich, Heinrich und Erkembert Stange einen Lehnsrevers aus, in welchem sie anerkennen, dass ihnen von dem Bischof Theoderich von Neuhaus gewisse Güter coniuncta manu zu Lehn verliehen wurden. (Cod. dipl, Mor. IV No. 266.) Die andere hierher gehörige Urkunde ist ein Lehnbrief des Bischofs Nikolaus v. 17. Januar 1398 (Cod. dipl. Mor. XII No. 119), worin dieser bekennt, er habe aus sonderlichen Gnaden dem Johannes, wiewohl er Priester sei, und Zwatan seinem ungesonderten Bruder, Söhnen des verstorbenen Menusches von Unilicz alle ihnen von ihrem Vater angefallenen Güter, welche bischöfliche Lehne und zwar rechte Mannlehne seien, ,mit gesampter hand" verliehen. - 2) Cod. dipl. Mor. XII, No. 584. Nikolaus Bischof von Olmütz gestattet im Jahre 1389, dass Heinrich von Fullstein und Gerbot von Katscher eine Gütervereinigung eingehen mit den Worten: „favimus - atque gracia speciali favemus, quod prefati fideles nostri se cum omnibus bonis ipsorum, quae a nobis in feodum tenent in presens, congressi sint et uniti ac unus in alterius bonis succedat, si quem ex eis ab hac luce migrare contigerit, legitimis feodi heredibus non relictis, nostre et ecclesie nostre iuribus ac serviciis semper salvis". Derselbe Bischof willigte in die Errichtung von Gütervereinigungen wegen der von ihm rührenden Lehne in den Jahren 1390 (Cod. dipl. Mor. XI No. 618), 1391 (das. XII No. 7 und No. 13) und 1395 (das. XII, No. 234). Beiläufig mag hier bemerkt sein, dass diese Urkunden in meiner Abhandl. zur Geschichte des sog. 
weit beschränktere als die des Landrechts. Nicht allein, dass sie sich allein auf die Lehngüter, welche die Mannen von dem Herrn besassen, der ihnen deren Zusammenlegung gestattete, erstreckten, sie betraf auch nur diejenigen Lehne, die ihnen im Zeitpunkte der lehnsherrlich genehmigten Errichtung der Gütervereinigung schon verliehen waren. Der künftige Erwerb von Lehnsbesitz fiel nicht darunter. Anlangend aber die rechtliche Bedeutung und die Wirkungen der unter den Lehnsmannen hergestellten Gemeinschaft, so fiel, nach dem Inhalte der Lehnsbriefe zu urtheilen, der Schwerpunkt in die damit eröffnete Möglichkeit einer Succession in das Lehn durch den längstlebenden Vasallen, wenn der andere mit ihm verbundene Vasall vor ihm sterben würde, ohne seinerseits lehnsfähige Nachkommen zu hinterlassen. Neben und ausser der von ihm erklärten Einwilligung in die von den Lehnsmannen unter einander vereinbarte und geschlossene Gütervereinigung betont deshalb der Bischof in seiner Eigenschaft als Lehnsherr noch ausdrücklich, er gewähre ihnen die besondere Gnade, dass einer in die Güter des andern solle folgen dürfen, wenn dieser ohne gesetzliche Leibeserben mit Tode abgehen würde ${ }^{1}$ ).

Dahingegen trat in der Zeit, in welche diese Gütervereinigungen und die darauf bezüglichen Olmützer Urkunden fallen, der Gedanke, dass damit eigentlich eine schon bei Lebzeiten bedeutsame, wenngleich auf den Bereich des Lehnrechts beschränkte Gütergemeinschaft unter den zu-

magdeburg. Lehnr. (a. a. O. S. 65 Note 1) irrig auf eine Gesammtbelehnung gedeutet worden sind. Auf diese bezieht sich nur die dort aus Cod. dipl. Mor. IV No. 266 angezogene Urkunde des Bischofs Theoderich vom J. 1280. (S. oben S. 37 Note 1.)

1) Man vgl. z. B. die Urk. des Bischofs Nikolaus vom 1. März 1395 betr. die Gütervereinigung zwischen Beneš von Turas und Peter und Johann, Söhne des Bohunek (Cod. dipl. Mor. XII No. 234) bei den Worten: „Nos - ipsorum supplicibus precibus benignius inclinati ad predictam congressionem et unionem sicut premittitur nostrum damus consensum benivolum pariter et assensum. Quibus eciam tenore presencium favimus de nostra scientia expresse atque gracia speciali favemus, quod prefati fideles nostri - unus in alterius bonis succedat, si quem ex eis ab hac luce migrare contigerit legitimis feodi heredibus non relictis, nostris et ecclesie nostre Olomucensis iuribus et serviciis semper salvis". S. auch die oben S. 37 Note 2 angeführte Urk. von 1389. 
sammengetretenen Lehnsmannen hergestellt sein sollte, mehr und mehr zurück. Wie im Landrecht war damals auch im Lehnrecht schon die Gütervereinigung, nicht zwar der Form ihrer Eingehung, wohl aber sonst der Hauptsache nach eine blosse Erbeinigung. Sie ging in ihren Wirkungen über die einer Erbeinigung nur insofern noch hinaus, als eine Veräusserung der eingeworfenen Lehngüter durch die einzelnen Theilnehmer an dritte ausserhalb der Gemeinschaft stehende Erwerber für gewöhnlich, und sofern nicht unter ihnen ein Anderes ausgemacht war, ausser der lehnsherrlichen Genehmigung die Zustimmung der übrigen mitverbundenen Lehnsmannen erforderte, sollte sie gültig und unanfechtbar vor sich gehen.

\title{
II. \\ Die Ueberlieferung der friesischen Küren und Landrechte.
}

\author{
Von \\ Herrn Privatdozenten Dr. Rudolf His \\ in Heidelberg.
}

Wenn die friesischen Rechtsquellen noch immer nicht diejenige Verwerthung gefunden haben, die sie zweifellos verdienen, so ist daran nicht am wenigsten die Art der Ueberlieferung schuld, in der diese Quellen auf uns gekommen sind. Seit K. v. Richthofen im Jahre 1840 die meisten dieser Quellen herausgegeben hat, ist für die Herstellung kritischer Texte so gut wie gar nichts geschehen.

$\mathrm{Zu}$ den wichtigsten und alterthümlichsten Quellen gehören die gemeinfriesischen Küren und Landrechte, die unter einander nahe verwandt sind und wahrscheinlich dem 11. Jahrhundert angehören ${ }^{1}$ ). Die Landrechte sind etwas

1) Heck, Der Ursprung der gemeinfriesischen Rechtsquellen, N. A. f. ält. deutsche Gesch. 17, 569-596. 